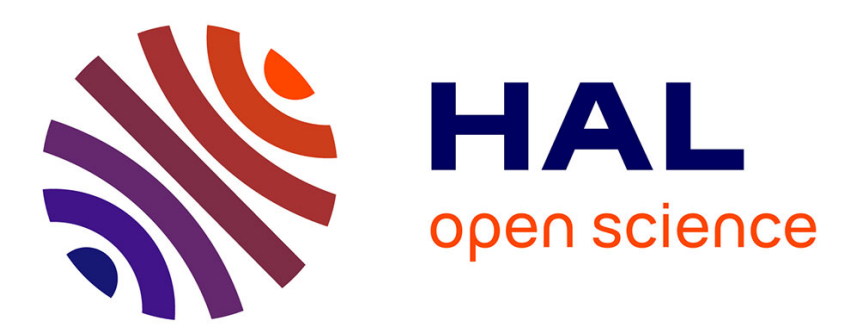

\title{
Solar 11-Year Cycle Signal in Stratospheric Nitrogen Dioxide-Similarities and Discrepancies Between Model and NDACC Observations
}

Shuhui Wang, King-Fai Li, Diana Zhu, Stanley Sander, Yuk Yung, Andrea Pazmino, Richard Querel

\section{To cite this version:}

Shuhui Wang, King-Fai Li, Diana Zhu, Stanley Sander, Yuk Yung, et al.. Solar 11-Year Cycle Signal in Stratospheric Nitrogen Dioxide-Similarities and Discrepancies Between Model and NDACC Observations. Solar Physics, 2020, 295 (9), pp.117. 10.1007/s11207-020-01685-1 . insu-02928896

\section{HAL Id: insu-02928896 \\ https://hal-insu.archives-ouvertes.fr/insu-02928896}

Submitted on 28 Jan 2021

HAL is a multi-disciplinary open access archive for the deposit and dissemination of scientific research documents, whether they are published or not. The documents may come from teaching and research institutions in France or abroad, or from public or private research centers.
L'archive ouverte pluridisciplinaire HAL, est destinée au dépôt et à la diffusion de documents scientifiques de niveau recherche, publiés ou non, émanant des établissements d'enseignement et de recherche français ou étrangers, des laboratoires publics ou privés. 


\section{Solar 11-Year Cycle Signal in Stratospheric Nitrogen Dioxide - Similarities and Discrepancies between Model and NDACC Observations}

Shuhui Wang ${ }^{1 *} \bullet$ King-Fai $\mathrm{Li}^{2} \bullet{\text { Diana } \mathrm{Zhu}^{3} \bullet \text { Stanley P. Sander }}^{4} \bullet$ Yuk Yung $^{5} \bullet$ Andrea Pazmino $^{6} \bullet$ Richard Querel ${ }^{7}$

${ }^{1}$ Joint Institute for Regional Earth System Science and Engineering, University of California, Los Angeles, California, USA

${ }^{2}$ Department of Environmental Sciences, University of California, Riverside, California, USA

${ }^{3}$ Harvard University, Cambridge, MA, USA (currently Mounds View High School)

${ }^{4}$ NASA Jet Propulsion Laboratory, California Institute of Technology, Pasadena, California, USA

${ }^{5}$ Divisions of Geological and Planetary Sciences, California Institute of Technology, Pasadena, California, USA

${ }^{6}$ LATMOS/IPSL, Sorbonne Université, UVSQ, CNRS, Paris, France

${ }^{7}$ National Institute of Water \& Atmospheric Research Ltd (NIWA), Lauder, New Zealand

"Corresponding author: Shuhui Wang (shuhui@ ucla.edu)

*(ORCID 0000-0001-5686-3604) 


\section{Abstract}

$\mathrm{NO}_{\mathrm{x}}\left(\mathrm{NO}_{2}\right.$ and $\left.\mathrm{NO}\right)$ plays an important role in controlling stratospheric ozone. Understanding the change in stratospheric $\mathrm{NO}_{\mathrm{x}}$ and its global pattern is important for predicting future changes in ozone and the corresponding implications on the climate. Stratospheric $\mathrm{NO}_{\mathrm{x}}$ is mainly produced by the reaction of $\mathrm{N}_{2} \mathrm{O}$ with the photochemically produced $\mathrm{O}\left({ }^{1} \mathrm{D}\right)$ and, therefore, it is expected to vary with changes in solar UV irradiance during the solar cycle. Previous studies on this topic, often limited by the relatively short continuous data, show puzzling results. The effect of the 1991 Pinatubo eruption might have caused interference in the data analysis. In this study, we examine the $\mathrm{NO}_{2}$ vertical column density (VCD) data from the Network for the Detection of Atmospheric Composition Change (NDACC). Data collected at 16 stations with continuous longterm observations covering the most recent Solar Cycles 23 and 24 were analyzed. We found positive correlations between changes in $\mathrm{NO}_{2} \mathrm{VCD}$ and solar Lyman- $\alpha$ over nine stations (mostly in the Northern Hemisphere) and negative correlations over three stations (mostly in the Southern Hemisphere). The other four stations do not show significant $\mathrm{NO}_{2}$ solar-cycle signal. The varying $\mathrm{NO}_{2}$ responses from one location to another are likely due to different geo-locations (latitude and altitude). In particular, two high-altitude stations show the strongest positive $\mathrm{NO}_{2}$ solar-cycle signals. Our 1D chemical-transport model calculations help explain the altitude dependence of $\mathrm{NO}_{2}$ response to the solar cycle. $\mathrm{NO}_{2}$ solar-cycle variability is suggested to play an important role controlling $\mathrm{O}_{3}$ at an altitude range from $\approx 20 \mathrm{~km}$ to near $60 \mathrm{~km}$, while $\mathrm{OH}$ solarcycle variability controls $\mathrm{O}_{3}$ at $40-90 \mathrm{~km}$. While observations show both positive and negative $\mathrm{NO}_{2}$ responses to solar forcing, the $1 \mathrm{D}$ model predicts negative $\mathrm{NO}_{2}$ responses to solar $\mathrm{UV}$ changes throughout the middle atmosphere. 3D global model results suggest complex roles of 
dynamics in addition to photochemistry. The energetic particle-induced $\mathrm{NO}_{2}$ variabilities could also contribute significantly to the $\mathrm{NO}_{2}$ variability during solar cycles.

\section{Introduction}

The 11-year solar cycle, also known as the sunspot cycle, is caused by the changes in magnetic features near the solar surface every $\approx 11$ years (e.g. Ermolli et al., 2013; Solanki et al., 2013). The solar magnetic activity is weak during a polarity change when the number of sunspots is the lowest. In contrast, the magnetic activity is the strongest in between two polarity changes when the number of sunspots is the highest. The solar irradiance also varies closely with the magnetic activity over the 11-year solar cycle. While the total solar irradiance (TSI) varies by only $0.1 \%$, in phase with the solar activity, solar ultraviolet (UV) irradiance varies up to $100 \%$ and has significant impacts on the terrestrial atmosphere through radiative heating and photochemistry.

Solar UV variability during 11-year cycles has been shown to cause quasi-periodic signals in temperature and many important atmospheric species such as ozone $\left(\mathrm{O}_{3}\right)$, hydroxyl $(\mathrm{OH})$, and nitrogen dioxide $\left(\mathrm{NO}_{2}\right)$ (e.g. Liley et al., 2000; Hood and Soukharev, 2006; Gruzdev, 2008, 2009; Remsberg, 2008, 2013; Haigh et al., 2010; Merkel et al., 2011; Beig et al., 2012; Swartz et al., 2012; Wang et al., 2013; Ball et al., 2014). These atmospheric responses directly or indirectly affect the $\mathrm{O}_{3}$ layer and climate. In the past decade, understanding the $\mathrm{O}_{3}$ response to solar forcing in the context of changes in anthropogenic forcings has been a key topic for studies on the Sunclimate interaction. Large disagreement among various space-borne and ground-based observational solar-cycle signals in middle atmospheric $\mathrm{O}_{3}$ and discrepancies between models and observations remain unresolved, although possible decadal satellite orbital drift was 
suggested to have contributed to these discrepancies ( $\mathrm{Li}$ et al., 2016). These discrepancies make it very challenging to quantify solar contribution to the climate change.

While the global $\mathrm{O}_{3}$ solar-cycle responses appear to be complex, involving direct $\left(\mathrm{O}_{3}\right.$ photolysis $)$ and various indirect processes (e.g. through photochemical variabilities in $\mathrm{O}_{3}$-controlling species such as $\mathrm{NO}_{\mathrm{x}}$ (primarily $\mathrm{NO}$ and $\mathrm{NO}_{2}$ ) and $\mathrm{HO}_{\mathrm{x}}$ (primarily $\mathrm{OH}$ and $\mathrm{HO}_{2}$ ), $\mathrm{O}_{2}$ photolysis, dynamics, and temperature), the middle atmospheric $\mathrm{O}_{3}$ solar-cycle variability is expected to be mostly controlled by photochemistry (Swartz et al., 2012). The variability in catalytic $\mathrm{HO}_{\mathrm{x}}$ cycles is suggested to dominate $\mathrm{O}_{3}$ solar-cycle changes in the upper stratosphere and the mesosphere $(\approx 40-80 \mathrm{~km})$ (Wang et al., 2013). At lower altitudes, the catalytic $\mathrm{NO}_{\mathrm{x}}$ cycle is expected to replace $\mathrm{HO}_{x}$ cycles in controlling $\mathrm{O}_{3}$ loss (e.g. Solomon, 1999). Other photochemical processes play a role as well. In particular, the enhanced effects of $\mathrm{O}_{2}$ photolysis (as a source of $\mathrm{O}_{3}$ ) and $\mathrm{O}_{3}$ photolysis (as a sink of $\mathrm{O}_{3}$ ) during solar maxima partially cancel out due to the opposite impacts on $\mathrm{O}_{3}$ variability. Between models using two solar spectral irradiance (SSI) inputs that differ by a factor of $2-6$ in UV variability during Solar Cycle 23 (from the Naval Research Laboratory model and various versions of measurements by Solar Radiation \& Climate Experiment, respectively), the vertically resolved latitudinal dependences of $\mathrm{O}_{3}$ solar-cycle signal show very different features at the upper middle atmosphere (above $40 \mathrm{~km}$ where $\mathrm{HO}_{\mathrm{x}}$ cycles dominate) and the lower middle atmosphere (where $\mathrm{NO}_{\mathrm{x}}$ cycles are important) (Swartz et al., 2012). More interestingly, the differences between models at these two altitude regions are in opposite directions, implying that $\mathrm{HO}_{\mathrm{x}}-\mathrm{O}_{3}$ chemistry and $\mathrm{NO}_{\mathrm{x}}-\mathrm{O}_{3}$ chemistry reponds to solar forcing in different ways and thus have different impacts on $\mathrm{O}_{3}$. It is therefore critical to quantify and understand the $\mathrm{NO}_{\mathrm{x}}$ variability as well as the $\mathrm{HO}_{\mathrm{x}}$ variability. Our previous work has examined 
$\mathrm{HO}_{\mathrm{x}}$ response to solar forcing and the corresponding impacts on $\mathrm{O}_{3}$ (e.g. Wang et al., 2013, 2015). In the present study, we focus on $\mathrm{NO}_{\mathrm{x}}$ response to solar cycles.

The primary source of stratospheric $\mathrm{NO}_{\mathrm{x}}$ is the reaction of $\mathrm{O}\left({ }^{1} \mathrm{D}\right)$, from $\mathrm{UV}$ photolysis, with $\mathrm{N}_{2} \mathrm{O}$, transported from the troposphere (reaction 1).

$$
\mathrm{N}_{2} \mathrm{O}+\mathrm{O}\left({ }^{1} \mathrm{D}\right) \rightarrow 2 \mathrm{NO}
$$

$\mathrm{O}\left({ }^{1} \mathrm{D}\right)$ mainly comes from $\mathrm{O}_{3}$ photolysis, while $\mathrm{N}_{2} \mathrm{O}$ photolysis also contributes:

$$
\begin{aligned}
& \mathrm{O}_{3}+\mathrm{h} v \rightarrow \mathrm{O}_{2}+\mathrm{O}\left({ }^{1} \mathrm{D}\right) \\
& \mathrm{N}_{2} \mathrm{O}+\mathrm{h} v \rightarrow \mathrm{N}_{2}+\mathrm{O}\left({ }^{1} \mathrm{D}\right)
\end{aligned}
$$

NO from reaction (1) can be converted into $\mathrm{NO}_{2}$ by reaction with $\mathrm{O}_{3}$ (reaction 4).

$$
\mathrm{NO}+\mathrm{O}_{3} \rightarrow \mathrm{NO}_{2}+\mathrm{O}_{2}
$$

The partitioning between $\mathrm{NO}$ and $\mathrm{NO}_{2}$ depends on ozone levels and other atmospheric conditions (e.g. UV photolysis rate).

$$
\begin{aligned}
& \mathrm{NO}_{2}+\mathrm{h} v \rightarrow \mathrm{NO}+\mathrm{O} \\
& \mathrm{O}+\mathrm{O}_{2}+\mathrm{M} \rightarrow \mathrm{O}_{3}+\mathrm{M}
\end{aligned}
$$

If all the atomic oxygen $(\mathrm{O})$ from reaction 5 recycles back to $\mathrm{O}_{3}$ through reaction 6 , the sum of reactions $4-6$ would have no effect on $\mathrm{O}_{3}$. However, reaction 7 takes $\mathrm{O}$ away.

$$
\mathrm{NO}_{2}+\mathrm{O} \rightarrow \mathrm{NO}+\mathrm{O}_{2}
$$

The combined result of reactions $4+7$ yield $\mathrm{O}_{3}+\mathrm{O} \rightarrow 2 \mathrm{O}_{2}$, leading to a net loss of $\mathrm{O}_{3}$ (Jacob, 1999). This catalytic $\mathrm{NO}_{\mathrm{x}}$ reactions cycle effectively destroys $\mathrm{O}_{3}$ without changing the level of $\mathrm{NO}_{\mathrm{x}}$ 
Therefore, the solar UV variability directly and indirectly affects stratospheric $\mathrm{NO}_{2}$ level, and the variation of stratospheric $\mathrm{NO}_{2}$ has important impacts on $\mathrm{O}_{3}$. More detailed description of the middle atmospheric $\mathrm{NO}_{\mathrm{x}}-\mathrm{O}_{3}$ chemistry can be found in Brasseur and Solomon (2005).

In addition to the photochemical sources and sinks, at polar regions where energetic particle precipitation (EPP) has an important impact on the middle atmosphere, $\mathrm{NO}_{\mathrm{x}}$ species are also formed through complex ion chemistry (e.g. Rusch et al., 1981). The ion chemistry is trigured by the reactions of energetic electrons e* with $\mathrm{N}_{2}$ and $\mathrm{O}_{2}$, which produce $\mathrm{N}_{2}^{+}, \mathrm{N}^{+}, \mathrm{N}, \mathrm{O}^{+}$, and $\mathrm{O}$, followed by a series of interchange and recombination reactions. More detailed descriptions of the ion chemistry can be found in Rusch et al. (1981). The EPP-induced production of $\mathrm{NO}_{\mathrm{x}}$ can be transported downward into the upper stratosphere and affect the variabilities at high latitudes (e.g. Langematz et al., 2005; Semeniuk et al., 2011; Jackman et al., 2012).

Due to its sensitivity to solar UV changes, stratospheric $\mathrm{NO}_{2}$ variabilities are dominated by seasonal cycles. Dynamics-driven signals such as quasi-biennial oscillations (QBO) and El Niño-Southern Oscillation (ENSO) also contribute. A long-term trend resulting from the gradual increase of tropospheric $\mathrm{N}_{2} \mathrm{O}$ sources is another major factor. The more subtle solar-cycle response is buried under these mixed signals.

In this work, we use $\mathrm{NO}_{2}$ data from the international Network for the Detection of Atmospheric Composition Change (NDACC) to extract the solar-cycle signal. There have been past studies using NDACC $\mathrm{NO}_{2}$ data. However, they mostly focused on the long-term trend or other variabilities, with the solar-cycle signal as a side product. Some were conducted for individual 
stations (e.g. Liley et al., 2000; Hendrick et al., 2012), while others were conducted over relatively short periods due to the availability of continuous data at the time of the investigations (Gruzdev, 2008; 2009; Johnston et al., 1989). The latitudinal pattern of the extracted atmospheric response to solar irradiance (Gruzdev, 2008, 2009) appeared to be unclear, with large scatters of both positive and negative values. The possiple impacts of EPP on the extracted solar cycle signals at high latitudes were not discussed. Futher more, the analysis also included data during the years when stratospheric $\mathrm{NO}_{2}$ was largely affected by the Pinatubo eruption. The recovery of $\mathrm{NO}_{2}$ levels after the eruption took as long as five years, which could potentially affect the extracted solar-cycle signals. A more recent study (Gruzdev, 2014) focused on the Pinatubo effect on $\mathrm{NO}_{2}$ in the context of the solar cycle. The summary of observed solar-cycle variability in $\mathrm{NO}_{2}$ shows a complex latitudinal pattern (both positive and negative responses were observed) with large uncertainties, while a 2D model used by Gruzdev (2009) predicted a weak negative response almost everywhere except over the southern polar region. These discrepancies were not resolved. No implications for the corresponding $\mathrm{O}_{3}$ changes were given.

It has been another five years since the latest research on the $\mathrm{NDACC} \mathrm{NO}_{2}$ response to solar cycles. Many stations now have data that cover the two most recent solar cycles, excluding earlier years when the interference of Pinatubo eruption has to be considered. We are in a much better position to revisit this issue and provide updated evidence to help resolve the puzzle.

Our primary goals are: i) to verify earlier findings of the $\mathrm{NO}_{2}$ solar cycle signal using updated and longer time series of NDACC measurements; ii) to understand the photochemical mechanisms that govern the $\mathrm{NO}_{\mathrm{x}}$ variability in response to solar $\mathrm{UV}$ changes during solar cycles 
and the corresponding impacts on $\mathrm{O}_{3}$ using our 1D photochemical model; iii) to evaluate the importance of other processes (in particular, dynamics) based on the comparison of observational signals and the photochemical models (both 1D and 3D).

\section{Data Description}

The NDACC is composed of over 70 remote-sensing research stations that provide long-term observations of atmospheric species around the globe. To ensure the consistency and continuity of the data analysis, we focus on stations with long-term, continuous measurements of $\mathrm{NO}_{2}$ total vertical column density (VCD) with the same experimental technique (UV-Visible spectroscopy). The data are publicly available at www.ndaccdemo.org/. Sixteen stations with two, or nearly two, complete solar cycles of UV-visible $\mathrm{NO}_{2}$ data since 1996 are selected. Assuming that the recovery of $\mathrm{NO}_{2}$ after the Pinatubo eruption needed no more than five years, our analysis using $\mathrm{NO}_{2}$ data after 1996 should have minimal interferences from the Pinatubo effect. The locations and altitudes of these stations are shown in Table 1. Most of these NDACC stations are located at remote areas far from pollution sources or at high altitudes (above the boundary layer), which helps minimize the tropospheric contribution to the total $\mathrm{NO}_{2} \mathrm{VCD}$. The observed $\mathrm{NO}_{2} \mathrm{VCD}$ is often assumed to be mostly from the stratosphere. Ideally, long-term global $\mathrm{NO}_{2}$ vertical profile measurements would be the best for investigating the detailed vertical structure of $\mathrm{NO}_{2}$ variabilities. The currently available long-term $\mathrm{NO}_{2}$ data from satellite instruments are often provided as total columns and partial columns in the stratsphere and the troposphere. The partial column retrieval generally requires a combined modeling/retrieval/assimilation approach, with the stratospheric part being estimated through assimilation (e.g. Boersma, et al., 2011; Dirksen et al., 2011). Some limb-viewing satellite 
instruments, e.g. the SCanning Imaging Absorption spectroMeter for Atmospheric CHartographY (SCIAMACHY) (e.g. Bauer et al., 2012), provide $\mathrm{NO}_{2}$ vertical profile measurements. However, they are generally not long enough for solar cycle studies. The latitudinal coverage is often uneven and it takes multiple days to have a global coverage. There also have been some partical column measurements at selected NDACC stations during certain time periods, but we are not able to find continuous long-term data records that are good enough for investigating variabilities on the solar cycle time scale.

For solar UV irradiance, we use the long-term composite of the solar Lyman- $\alpha$ flux (at 121.5 nm) from the Laboratory for Atmospheric and Space Physics (LASP) as a proxy, (lasp.colorado.edu/lisird/data/composite_lyman_alpha/). This Lyman- $\alpha$ composite is built upon measurements from multiple satellite instruments as well as model simulations in order to construct a long-term time series history of the full-disk integrated solar irradiance over 121 $122 \mathrm{~nm}$. Measurements are used whenever they are available and of sufficient quality. (Woods et al., 2000). The values are all scaled to match the reference levels of the SOlar Stellar Irradiance Comparison Experiment (SOLSTICE) on board the Solar Radiation and Climate Experiment (SORCE) as discussed by Machol et al. (2019).

\section{Model Description}

Both 1D and 3D models are used in this study. The 1D model is the Caltech/JPL chemicaltransport model. It covers the atmosphere from the surface to $130 \mathrm{~km}$ in 65 layers. It includes vertical transport (including eddy, molecular, and thermal diffusion) and coupled radiative transfer (Allen, Yung, and Waters, 1981; Allen, Lunine, and Yung, 1984; Yung and DeMore, 
1999; Mills et al., 2003). It currently has over 100 species and over 460 chemical reactions. This model has been used to investigate the sensitivity of middle atmospheric $\mathrm{OH}$ to solar UV change (Wang et al., 2013).

To get hints about the dynamical influence that is not represented in the 1D model, we also examine the $\mathrm{NO}_{2}$ solar response simulated in the Whole Atmosphere Community Climate Model (WACCM). How the solar cycle interacts with the dynamics is beyond the scope of this work. To focus on the $\mathrm{NO}_{2}$ response alone, we therefore use the WACCM Specified Dynamics (RefC1SD) simulations that have been submitted to the Chemistry-Climate Model Initiative (CCMI: Morgenstern et al., 2017). The outputs of the simulation are publicly accessible from the Climate Data Gateway at the US National Center for Atmospheric Research (www.earthsystemgrid.org). The simulation is performed using WACCM version 4 (Marsh et al., 2013), where the wind and temperature below the altitude of the $1 \mathrm{hPa}$ pressure level are driven by the Modern-Era Retrospective analysis for Research and Applications (MERRA) from 1970 to 2014. The free simulation of the dynamics from this altitude to the lower thermosphere closely reproduces the observations (Garcia et al., 2014). The solar cycle in the model is driven by the 10.7-cm solar radio flux (Tapping, 2013). The aurora energetic particle precipitation (EPP) events are parameterized using the $K_{p}$ planetary geomagnetic index (Maeda et al ., 1989). Peck et al. (2015) shows that a doubling of the EPP-induced increase in the polar stratospheric $\mathrm{NO}_{\mathrm{y}}$ from solar minimum to solar maximum in WACCM4 does not significantly alter the associated changes in temperature and wind. Thus, as we will show, the RefC1SD run captures the important meridional structure of the $\mathrm{NO}_{2}$ solar response and provides insights about the NDACC observations. 


\section{Data Analysis}

The extraction of the relatively weak $\mathrm{NO}_{2}$ solar-cycle response among other variability is challenging. Simple methods, such as the multiple linear regression used in previous studies (Gruzdev, 2008, 2009, 2014), usually assume that $\mathrm{NO}_{2}$ responds to the solar forcing linearly, which may not hold in reality. Modern machine-learning algorithms, in contrast, are designed to detect nonlinear signals without any assumptions. In this work, we separate solar-cycle signals from other variabilities using the Empirical Mode Decomposition (EMD) (Huang et al., 1998). EMD is an adaptive time-space analysis method for decomposing a non-stationary and nonlinear time series into different components of different characteristic periods, called the Intrinsic Mode Functions (IMFs) by the sifting process. The uncertainties of the IMFs can be estimated by creating an ensemble of IMFs that are obtained by a set of white noise to the raw time series, a procedure known as the ensemble EMD (EEMD) (Wu and Huang, 2009). The EEMD can better detach climate signals of different time scales naturally without prior information than the EMD (Kobayashi-Kirschvink et al., 2012; Shi et al., 2013; Newman et al., 2016).

The original $\mathrm{NO}_{2} \mathrm{VCD}$ measurements generally have precision errors of order of a few percent. Before running EEMD analysis, we applied a monthly mean to the data to smooth out the day-today noise. Through error propagation, the precision error bars became much smaller in the monthly mean data (on the order of $0.01 \%$ ) and also generally small compared to the solar-cycle signals that we aim to extract. The monthly averaged $\mathrm{NO}_{2} \mathrm{VCD}$ data are decomposed into a number of IMFs with various temporal frequencies. The IMF that has a period closest to 11 years is identified as the $\mathrm{NO}_{2}$ solar response. 
The results over station Issyk-Kul are shown in Fig. 1 as an example. Left panels are $\mathrm{NO}_{2}$ signals, with the raw data on the top panel and decomposed modes (IMFs) below. Right columns show the corresponding time period. In this case, IMFs 1 and 2 represent the semi-annual (mixed with noise) and annual cycles (the dominant component in the original time series), respectively. IMF 3 is a mixture of QBO with annual signal. IMF 4 is related to ENSO. IMF 5 is identified as the solar 11-year cycle signal, with two $\mathrm{NO}_{2}$ peaks in Solar Cycles 23 and 24 (around 2002 and 2013), respectively. IMFs 6 and 7 are longer-term variabilities with a time period close to 20 years. The last mode, which is the residual of the EEMD, suggests a secular change that is most likely associated with an increasing trend that is consistent with the increase of $\mathrm{N}_{2} \mathrm{O}$ from the troposphere.

While the majority of the selected NDACC stations show similar EEMD results, a few stations show significantly different features of IMFs. For example, Fig. 2 illustrates the decomposition of $\mathrm{NO}_{2}$ variabilities at station Kerguelen. Similarly, the $\mathrm{NO}_{2}$ variability is dominated by the annual cycle (IMF 2), with significant contributions from QBO (IMF 3), and ENSO (IMF 4). However, in contrast to the case of station Issyk-Kul, the extracted solar-cycle mode (IMF 5) over Kerguelen appears to have an opposite sign from the solar cycle, with minimum $\mathrm{NO}_{2}$ levels around solar peaks (in 2002 and 2013 - 2014) and maximum $\mathrm{NO}_{2}$ levels at the solar minima. The resulting long-term secular change (shown as the residual mode) is generally negative, which is opposite to the apparent trend over station Issyk-Kul and cannot be explained by the increase of $\mathrm{N}_{2} \mathrm{O}$ from troposphere. 
Earlier studies focusing on the stratospheric $\mathrm{NO}_{2}$ long-term trend have reported stratospheric $\mathrm{NO}_{2}$ trends with a wide range from a large positive number that is twice the $\mathrm{N}_{2} \mathrm{O}$ increasing trend (Liley et al., 2000) to a negative number in both ground-based measurements and spacecraft data (Hendrick, et al., 2012). These discrapencies have not been completely understood. Our EEMD analysis over NDACC stations also found both positive and negative long-term changes (or apparent trends) in $\mathrm{NO}_{2}$. Note that these signals are a side-product of our solar-cycle analysis, produced as the residual after separating $\mathrm{NO}_{2}$ variabilities of different time scales. The lowfrequency IMFs suggest possible longer-term variabilities (e.g. IMFs 6 and 7 in Fig. 1, IMF 6 in Fig. 2) that could contribute to the residual, if not carefully separated. In addition, although NDACC stations are mostly located far from local tropospheric pollution, we cannot completely rule out the possible contribution from tropospheric $\mathrm{NO}_{2}$ which has different trends than in the stratosphere. An accurate evaluation of the stratospheric $\mathrm{NO}_{2}$ trend requires data records that are much longer than $20-30$ years and is not the focus of this article.

To quantify the sensitivity of $\mathrm{NO}_{2}$ solar-cycle signals with respect to the magnitude of solar UV changes, the IMF associated with the $\mathrm{NO}_{2}$ solar response is correlated with the solar UV irradiance. The daily Lyman- $\alpha$ data are averaged into monthly means to effectively remove the large oscillations due to solar 27-day rotational cycles and are correlated with the corresponding $\mathrm{NO}_{2}$ variabilities. Figure 3 shows the scatter plots of $\mathrm{NO}_{2} \mathrm{VCD}$ changes versus the solar Lyman$\alpha$ irradiance changes over Issyk-Kul (Fig. 3a) and Kerguelen (Fig. 3b). The slope of the linear regression represents the sensitivity of $\mathrm{NO}_{2} \mathrm{VCD}$ to the changes in solar Lyman- $\alpha$. The correlation coefficient $\left[R^{2}\right]$ represents the goodness of the linear fit and is a measure of the confidence of the correlation. As shown in Fig. 3a, the result over station Issyk-Kul suggests a 
strong positive response of $\mathrm{NO}_{2}$ to solar $\mathrm{UV}$ changes (near $10 \%$ increase in $\mathrm{NO}_{2} \mathrm{VCD}$ with $100 \%$ increase in solar Lyman- $\alpha$ ). The correlation of signals over station Kerguelen shows a negative slope, suggesting a near $3 \%$ decreasing of total $\mathrm{NO}_{2}$ with a $100 \%$ increase in solar Lyman- $\alpha$ (Fig. 3b). Note that although the extracted $\mathrm{NO}_{2}$ signal has a significant correlation with solar UV, the correlation sometimes shows non-statistical features when the variability of $\mathrm{NO}_{2}$ does not perfectly align with the timing of solar maxima and minima.

We examined $\mathrm{NO}_{2}$ data from all 16 stations. Nine of the stations show significant positive solarcycle responses, with three stations showing negative or weak signals. For the remaining four stations, we did not find any clear correlation between $\mathrm{NO}_{2}$ and Lyman- $\alpha$. The analysis results are summarized in Table 1.

\section{Discussions on Analysis Results}

EEMD is able to decompose a raw time series into various quasi-periodic signals, but the decompositions may be affected by strong sporadic events. For $\mathrm{NO}_{2}$, one of the most significant interferences comes from major volcano eruptions that inject large amounts of aerosols into the stratosphere and cause reduction in $\mathrm{NO}_{2}$ levels. The Ultra Plinian of Mount Pinatubo eruption on 15 June 1991 produced the second-largest terrestrial eruption of the 20th century, resulting a remarkable reduction in stratospheric $\mathrm{NO}_{2}$. The recovery of $\mathrm{NO}_{2}$ levels after the major eruption could take a few years. Earlier studies used all available data at the time, with the Pinatubo years in the middle of the time series (e.g. Gruzdev, 2009, 2014). While previous analysis was very carefully carried out to simulate the corresponding aerosol impacts by using aerosol optical depth as a proxy in the multi-variable regression analysis, possible interference of the Pinatubo effect 
may not be completely ruled out. Shorter time series outside the multi-year window of Pinatubo effect could also lead to larger uncertainties in the resulting solar-cycle signals in $\mathrm{NO}_{2}$. Therefore, to minimize the interference of Pinatubo eruption, our EEMD analysis only includes data starting from 1996, assuming that $\mathrm{NO}_{2}$ levels had fully recovered by 1996 . The time series from 1996 to the present covers the entire Solar Cycles 23 and 24.

The results of our analysis are summarized into latitudinal-dependence patterns in Fig. 4 and compared to those of Gruzdev (2014). Note that our results are the $\mathrm{NO}_{2} \mathrm{VCD}$ sensitivity to $100 \%$ Lyman- $\alpha$ change (left axis), while the earlier study (right axis) showed the estimated average $\mathrm{NO}_{2} \mathrm{VCD}$ changes between solar minimum and solar maximum for the investigated time period (the Lyman- $\alpha$ change varies from one cycle to another). In the earlier study, the extracted $\mathrm{NO}_{2}$ solar-cycle signal had no clear latitudinal dependence. Stations located at similar latitudes often showed completely different results, with both positive and negative $\mathrm{NO}_{2}$ changes. The scatter range of the signal magnitude was wide in both hemispheres. In the present study, the sign and magnitude of $\mathrm{NO}_{2}$ solar-cycle signal do not seem to have a clear latitudinal dependence either. However, most of the stations with strong positive $\mathrm{NO}_{2}$ responses to solar UV are located in the Northern Hemisphere, while the Southern Hemisphere stations show either weak or negative $\mathrm{NO}_{2}$ solar-cycle signals. Note that some stations are located at high latitudes where the complex $\mathrm{NO}_{\mathrm{x}}$ enhancement due to EPP in the mesosphere and the downward transport into the stratosphere (e.g. Langematz et al., 2005; Semeniuk et al., 2011; Jackman et al., 2012) could contribute significantly to the extracted solar-cycle signal. While the impact due to EPP typically lasts a few days. the more frequent and stronger EPP events duing solar maximum lead to higher $\mathrm{NO}_{2}$ values in some of the winter months. Thus some of the extracted solar-cycle signal 
in $\mathrm{NO}_{2}$ at high latitudes could include the impacts of EPP. Moreover, the strongest solar proton events (SPEs) often occur during the decline phase of the solar cycle, making the impacts of these events and the UV-induced solar-cycle signal slightly out of phase. At low latitudes, the impacts of EPP are generally small.

In addition to latitude, the altitude of the station also contributes to the differences in $\mathrm{NO}_{2}$ solarcycle signal. Figure 5 shows the $\mathrm{NO}_{2}$ solar-cycle signal as a function of both latitude and altitude, based on the results summarized in Table 1. The scatters are color coded according to the percentage change in $\mathrm{NO}_{2} \mathrm{VCD}$ with $100 \%$ change in solar Lyman- $\alpha$. The sizes of the scatters are proportional to the correlation coefficient $\left[R^{2}\right]$, which is an indicator of the statistical significance of the corresponding $\mathrm{NO}_{2}$ signal. It is clearly shown that the two stations located at the highest altitudes, Issyk-Kul (1650 m, red circle) and Jungfraujoch (3580 m, orange circle), have the largest positive $\mathrm{NO}_{2}$ response to solar $\mathrm{UV}$. The correlation coefficients for these stations are also among the highest. Although NDACC stations are mostly at remote areas far from local tropospheric pollution, we cannot completely rule out the possible contribution from tropospheric $\mathrm{NO}_{2}$. The $\mathrm{NO}_{2}$ total $\mathrm{VCD}$ measured at high-altitude stations does not include the lower part of the troposphere where pollution sources are. The variability signal is therefore more likely to be for stratospheric $\mathrm{NO}_{2}$ only. Thus the solar-cycle signals at these high altitude stations appear to be the strongest. For stations at much lower altitudes but at very remote locations, for example the Kerguelen Islands (located in the Southern Indian Ocean, thousands miles away from the nearest continent), the correlation is as strong as those from the highaltitude stations. However, the magnitude of the solar cycle response is much smaller. The background tropospheric $\mathrm{NO}_{2}$ at such remote locations are not expected to show significant 
variations that could interfere with our solar cycle analysis, but could dilute the overall solar cycle response, which is reflected in the small solar-cycle signal with a large correlation coefficient (see the large purple scatter at $49^{\circ} \mathrm{S}$ in Fig. 5). For the low-altitude stations that are not as remote, the correlations are generally weaker (shown by the smaller size of the scatters in Fig. 5).

\section{Comparison with Models}

To help understand the mechanisms that control $\mathrm{NO}_{2}$ responses to solar UV changes and to predict the corresponding impacts on $\mathrm{O}_{3}$, we performed 1D photochemical-transport model runs to study the vertical and spectral distribution of $\mathrm{NO}_{2}$ sensitivity to solar UV change. The Caltech/JPL 1D model covers from the surface to $130 \mathrm{~km}$, with over 100 species and over 460 chemical reactions. It is currently configured for the mid-latitude conditions at Equinox.

Figure 6a shows the vertically and spectrally resolved $\mathrm{NO}_{2}$ response to changes in solar UV irradiance. The spectral $\mathrm{NO}_{2}$ response is defined as the ratio of the percentage change in $\mathrm{NO}_{2}$ to the percentage change in solar photon flux at the top of the atmosphere $\left(\%-\left[\mathrm{NO}_{2}\right] / \%\right.$-photon flux). Using the percentage solar UV change as the basis, we can avoid the impact of the large discrepancy in SSI variabilities (as mentioned in Sect. 1). By integrating the $\mathrm{NO}_{2}$ change across the wavelength window from solar minimum to solar maximum, we calculated the overall $\mathrm{NO}_{2}$ solar-cycle variability at each altitude (Fig. 6b). The corresponding impacts on $\mathrm{O}_{3}$ purely due to the $\mathrm{NO}_{2}$ solar-cycle changes are also calculated and shown in Fig. 6c. The largest impact on $\mathrm{O}_{3}$ is around $40 \mathrm{~km}$, with the altitude range extending from about $20 \mathrm{~km}$ to near $60 \mathrm{~km}$. Throughout this highlighted altitude range, our model results in Fig. $6 \mathrm{~b}$ show a negative $\mathrm{NO}_{2}$ solar-cycle 
signal, which means less $\mathrm{NO}_{2}$ at solar maximum than at solar minimum, which leads to more $\mathrm{O}_{3}$ at solar maximum than minimum (Fig. 6c).

In our previous investigations on $\mathrm{OH}$ (Wang et al., 2013), model results suggested that the $\mathrm{OH}$ solar-cycle responses have impacts on $\mathrm{O}_{3}$ above $40 \mathrm{~km}$ (the highlighted region is $\approx 40-90 \mathrm{~km}$ ). More $\mathrm{OH}$ (Fig. 7e) leads to less $\mathrm{O}_{3}$ (Fig. 7f) at solar maximum than at solar minimum.

Comparing the features in the top panels and the bottom panels in Fig.s 6, the $\mathrm{NO}_{2}$ and $\mathrm{OH}$ solarcycle effects on $\mathrm{O}_{3}$ have completely opposite directions. Their combined effects determine the solar-cycle change in middle atmospheric $\mathrm{O}_{3}$. In the upper middle atmosphere, $\mathrm{OH}$ effects dominate and more $\mathrm{OH}$ leads to less $\mathrm{O}_{3}$. Between $40-60 \mathrm{~km}$ where the two effects overlap, they partially cancel out, leading to smaller $\mathrm{O}_{3}$ variabilities due to solar cycles. At the lower part of the middle atmosphere, below $40 \mathrm{~km}, \mathrm{NO}_{2}$ effects plays a more important role.

In order to fully understand the chemical mechanisms behind the $\mathrm{NO}_{2}$ solar-cylce response pattern in Fig. 6a, we investigated the precursors of $\mathrm{NO}_{2}$ and the key chemical reation rates. Fig. 7 shows the vertically and spectrally resolved response of the key species and chemical reactions to the changes in solar UV irradiance. The spectral response functions highlight individual chemical reactions involved in the $\mathrm{NO}_{\mathrm{x}}$ solar-cycle responses, which helps isolate the dynamical impacts in 3D models.

The stratospheric $\mathrm{NO}_{2}$ mainly comes from reaction 4, the reaction of $\mathrm{NO}$ (Fig. 7b) with $\mathrm{O}_{3}$ (Fig. 7d), with $\mathrm{NO}$ being produced through reaction 1, the reaction of $\mathrm{N}_{2} \mathrm{O}$ (Fig. 7c) with $\mathrm{O}\left({ }^{1} \mathrm{D}\right.$ ) (Fig. 
7e). As seen in Fig. 7 a, with the increasing solar UV flux at solar maxima, $\mathrm{NO}_{2}$ shows a strong negative response around $200 \mathrm{~nm}$ throughout the middle atmosphere and an extended positive response around $300 \mathrm{~nm}$ thoughout the middle atmosphere, especially in the stratosphere. A smaller positive response at $35-55 \mathrm{~km}$ and a smaller negative response at $40-60 \mathrm{~km}$ are also shown. These responses partially cancel out with each other, resulting the overall negative vertical profile of $\mathrm{NO}_{2}$ solar-cycle signal in Fig. $6 \mathrm{~b}$.

The features of $\mathrm{NO}_{2} \mathrm{UV}$ responses in Fig. 7a clearly resemble the responses of its production rate through reaction $4\left(\mathrm{NO}+\mathrm{O}_{3} \rightarrow \mathrm{NO}_{2}+\mathrm{O}_{2}\right)$ in Fig. 7f. The combination of the responses in $\mathrm{NO}$ (Fig. 7b) and $\mathrm{O}_{3}$ (Fig. 7d) thus explains the patterns in Fig. 7f as well as Fig. 7a. To further understand Fig. 7b, the NO responses to UV changes, we need to analyze its source species $\mathrm{N}_{2} \mathrm{O}$ and $\mathrm{O}\left({ }^{1} \mathrm{D}\right)$. When solar $\mathrm{UV}$ increases, $\mathrm{O}\left({ }^{1} \mathrm{D}\right)$ is enhenced via two photolysis reactions 2 and 3: $\mathrm{O}_{3}$ $+h v \rightarrow \mathrm{O}_{2}+\mathrm{O}\left({ }^{1} \mathrm{D}\right)$ and $\mathrm{N}_{2} \mathrm{O}+h v \rightarrow \mathrm{N}_{2}+\mathrm{O}\left({ }^{1} \mathrm{D}\right)$. The enhanced $\mathrm{N}_{2} \mathrm{O}$ loss through its direct photolysis, reaction 3, leads to the strong negative $\mathrm{N}_{2} \mathrm{O}$ response around $200 \mathrm{~nm}$. The decreasing effect at lower altitudes is clearly due to the rapidly decreasing UV as light penetrating through the stratosphere. The much weaker negative $\mathrm{N}_{2} \mathrm{O}$ response around $300 \mathrm{~nm}$ is most likely a result of the enhanced $\mathrm{N}_{2} \mathrm{O}$ loss through its reaction with increasing $\mathrm{O}\left({ }^{1} \mathrm{D}\right)$. This hypothesis is confirmed by the strong positive $\mathrm{O}\left({ }^{1} \mathrm{D}\right.$ ) response (Fig. 7e) and the negative $\mathrm{O}_{3}$ response (Fig. $7 \mathrm{~d}$ ) at the same wavelengths with very similar patterns. The other positive $O\left({ }^{1} \mathrm{D}\right)$ response at shorter wavelengths (below $240 \mathrm{~nm}$ ) and above $35 \mathrm{~km}$ is due to the enhanced photolysis of $\mathrm{O}_{2}$ at the corresponding wavelengths. The negative $\mathrm{O}\left({ }^{1} \mathrm{D}\right)$ response at below $35 \mathrm{~km}$ is a typical result of the atmospheric shielding effect - The enhanced $\mathrm{O}_{3}$ during solar maxima at these wavelengths (see Fig. 7d) blocks the incoming short-wavelength UV from further penetrating into the lower 
part of the stratosphere. This shielding effect results in less short-wavelength UV available at below $35 \mathrm{~km}$ for $\mathrm{O}_{2}$ photolysis and $\mathrm{O}\left({ }^{1} \mathrm{D}\right)$ production at the corresponding wavelengths. These combined effects of $\mathrm{N}_{2} \mathrm{O}$ and $\mathrm{O}\left({ }^{1} \mathrm{D}\right)$ result in the $\mathrm{NO}$ responses to solar $\mathrm{UV}$ changes. NO quickly reacts with $\mathrm{O}_{3}$ in the $\mathrm{NO}_{x}$ cycle; updating the equilibrium state with $\mathrm{NO}_{2}$ and Thus the reaction between $\mathrm{NO}$ and $\mathrm{O}_{3}$ determines the changes in $\mathrm{NO}_{2}$. The spectral response of $\mathrm{NO}_{2}(\mathrm{Fig}$. 7a) is therefore very similar to those of the direct $\mathrm{NO}_{2}$ production rate through $\mathrm{NO}+\mathrm{O}_{3} \rightarrow \mathrm{NO}_{2}+\mathrm{O}_{2}$ (Fig. 7f); the latter is close to a direct sum of the spectral responses in $\mathrm{NO}$ and $\mathrm{O}_{3}$ (Fig.s $7 \mathrm{~b}$ and 7d), as expected in the photochemical equilibrium. This analysis decomposes the chemical machnisms governing the $\mathrm{NO}_{\mathrm{x}}$ solar-cycle responses, which is very important for understanding the $\mathrm{NO}_{2}$ variabilities in more complex $3 \mathrm{D}$ models and to identify the impacts from dynamics.

While the $1 \mathrm{D}$ model predicts a negative $\mathrm{NO}_{2}$ solar-cycle signal throughout the highlighted altitude region $(20-60 \mathrm{~km})$ where $\mathrm{NO}_{2}$ plays an important role controlling $\mathrm{O}_{3}$, most $\mathrm{NDACC}$ stations show positive $\mathrm{NO}_{2}$ solar-cycle signals in the observed $\mathrm{NO}_{2} \mathrm{VCD}$. In the previous study by Gruzdev (2014), the comparison between NDACC observations and 2D model results showed similar discrepancies.

Due to the strong diurnal variability, $\mathrm{NO}_{2}$ as well as the solar zenith angle (SZA) change rapidly during sunrise and sunset when $\mathrm{NDACC} \mathrm{NO}_{2} \mathrm{VCD}$ measurements are carried out. The changes in the observed $\mathrm{NO}_{2}$ solar-cycle signal during the measurement time window have to be quantified. We did sensitivity studies with the $1 \mathrm{D}$ model to investigate the sensitivity of $\mathrm{NO}_{2}$ solar-cycle signals to the time of day. Figure 8 shows the calculated $\mathrm{NO}_{2}$ variability between solar maximum and solar minimum at different times (and thus different SZAs) around sunrise 
and sunset. The resulting vertical profiles are somewhat different in the magnitude. However, the negative sign remains for all cases. Therefore, the fact that measurements might not be always carried out at exactly the same SZA could possibly introduce additional uncertainties to the magnitude of the extracted solar-cycle signal, but will not change the sign of it.

Besides geo-locations (altitude and latitude) and the measurement time, other factors that could also contribute to the observed signals in Fig. 5 include the distance from major pollution sources and long-range atmospheric transport. The impacts due to these factors may be examined using global 3D chemistry-transport models.

As a preliminary investigation, Fig. 9 shows the zonally averaged $\mathrm{NO}_{2}$ solar-cycle signals extracted from the CCMI WACCM-SD model run from 1979 to 2014. In order to investigate the contribution of $\mathrm{NO}_{2}$ variability in each vertical grid to the total VCD $\mathrm{NO}_{2}$ variability, we present the model calculated $\mathrm{NO}_{2}$ solar-cycle signal as the corresponding $\mathrm{NO}_{2} \mathrm{VCD}$ changes (\%) per $100 \%$ change in Lyman- $\alpha$ changes at each vertical interval of $1 \mathrm{~km}$. The patterns in different seasons are shown in the four panels: 9a (December - February), 9b (March - May), 9c (June August), and 9d (September - November). There is a seasonal difference on top of the vertical and latitudinal patterns. At mid-latitudes, the $\mathrm{NO}_{2}$ solar-cycle signal is generally negative or very small (in agreement with the 1D model results), except for the thin layer at the bottom of the middle atmosphere $(40-100 \mathrm{hPa})$ where $\mathrm{NO}_{2}$ solar-cycle signal has a significant positive value. This positive $\mathrm{NO}_{2}$ solar-cycle signal is especially strong at the tropical region and is generally stronger in the northern hemisphere than in the southern hemisphere, which leads to an overall positive $\mathrm{NO}_{2}$ change in the total column at the tropics and some part of the northern mid-latitude. 
This is consistent with the mostly positive solar-cycle signals in $\mathrm{NO}_{2} \mathrm{VCD}$ data from NDACC stations in the northern hemisphere and the weak or negative signals in $\mathrm{NO}_{2} \mathrm{VCD}$ from stations in the southern hemisphere. The seasonal difference at these latitudes is not very strong. This layer of strong positive $\mathrm{NO}_{2}$ solar-cycle signal was not predicted in our $1 \mathrm{D}$ model or the $2 \mathrm{D}$ model used by Gruzdev (2014). Thus, the positive solar response in the $\mathrm{NO}_{2}$ column observed over the NDACC network is likely a result of the general circulation. The simpler 1D or 2D models are not adequate to reveal these complex features, resulting in the apparent discrepancies in $\mathrm{NO}_{2}$ solar-cycle variability between NDACC observations and 2D models as reported by Gruzdev (2014).

At high latitudes where the dynamics of polar vortex and the EPP effects play a crucial role (e.g. Langematz et al., 2005; Semeniuk et al., 2011), the model results show totally different patterns. The high-latitude $\mathrm{NO}_{2}$ variability is far more complex than at mid- to low-latitudes. The dramatic seasonal differences and the deep vertical extension of the high-latitude $\mathrm{NO}_{2}$ solar-cycle variability suggest significant impacts of $\mathrm{NO}_{2}$ intrusions from the mesosphere, especially during the polar winter (see the North Pole in Fig. 9a and the South Pole in Fig. 9c). Further investigations with models specialized in polar chemistry and transport (including polar vortex dynamics and accurate prescription of the solar proton events and energetic electron precipitation, etc.) are needed to fully understand the high-latitude $\mathrm{NO}_{2}$ variability. At mid- to low-latitudes where the contribution of mesospheric $\mathrm{NO}_{2}$ variability is much smaller, the observed total column $\mathrm{NO}_{2}$ variability comes mostly from the stratosphere.

To see how the complex responses in the 3D model may impact the ground-based observations, we integrate the WACCM-SD $\mathrm{NO}_{2}$ concentration from $250 \mathrm{hPa}$ to $0.7 \mathrm{hPa}$ (focus on the stratospheric variability) and calculate the ratio of $\%$ annual mean $\mathrm{NO}_{2}$ change and \% Lyman- $\alpha$ 
change over the 11-year solar cycle (shown in Fig. 10 as the blue-solid line). The annual average corresponds to a robust solar response that is expected if we had a globally dense surface network. The resultant $\mathrm{NO}_{2}$ solar response exhibits a double-well structure: there is a positive maximum of about $8 \%$ near the Equator due to the thin layer of positive $\mathrm{NO}_{2}$ changes in the lower stratosphere (shown in Fig. 9), and two negative minima of about $-3 \%$ in northern and southern subtropics due to photochemistry. Beyond $60^{\circ}$ latitude, the polar dynamics is dominant and the solar response is strongly positive. To further isolate the photochemical effect at low latitudes, we calculate the solar response in the upper stratospheric region from $10 \mathrm{hPa}$ to $0.7 \mathrm{hPa}$ (Fig. 10, pink-dashed line), which is predominantly negative of about $-3 \%$ below $60^{\circ}$ latitude. The tropical maximum is solely due to the lower stratospheric response, as is shown by the orange-dashed line in Fig. 10. For comparison, the upper-stratospheric response (pink-dashed line) agrees with the 2D model simulation used by Gruzdev (2009) (Fig. 10, green-thick line). We also integrate the $\mathrm{NO}_{2}$ column in our 1D model from $12 \mathrm{~km}$ to $50 \mathrm{~km}$. The $1 \mathrm{D}$ model result shows that, without any meridional circulation, the tropical solar response may be slightly more negative, which is $-3.4 \%$ in the diurnal average (Fig. 10, black triangle).

Lastly, we compare the simulated stratospheric $\mathrm{NO}_{2}$ solar-cycle response with the NDACC observations in Fig. 4. In contrast to Gruzdev's (2014) linear regression, our EMD-extracted more positive solar-cycle responses in the northern hemisphere agree better with the WACCM simulation, thus revealing the influence of EPP-induced $\mathrm{NO}_{2}$ in the northern stratosphere. However, the EMD-extracted solar-cycle responses from 4 stations in the southern hemisphere are much lower than the WACCM-SD simulation, suggesting that the observed EPP-induced stratospheric $\mathrm{NO}_{2}$ in the southern hemisphere is weaker than expected. To rule out the effect of 
the zonal averaging of the WACCM-SD simulation, we have performed another calculation using only the time series at model grid points closest to the four stations and verified that the simulated $\mathrm{NO}_{2}$ solar-cycle responses at those grid points remain the same as in the zonal averages. Unfortunately, there is not enough NDACC measurements of $\mathrm{NO}_{2}$ column to confirm the positive response in the tropical region.

The WACCM-SD result discussed above implies that dynamics in the tropical lower stratosphere and the polar stratosphere is the dominant contributing factor of the positive sign of the simulated $\mathrm{NO}_{2}$ solar-cycle responses. Note that the ground-based measurements of total column $\mathrm{NO}_{2}$ also consists of a significant fraction $(\approx 20 \%$ or less, depending on the altitude of the station) from the tropospheric that could be affected by a number of factors such as urban sources (less possible due to the remote location of many of the stations) and the tropospheric circulation. The local $\mathrm{NO}_{2}$ solar responses over the NDACC stations likely contributed to the more scattered variability in Fig. 4 than the smooth responses predicted by photochemistry and WACCM-SD. The double-well structure as simulated in WACCM-SD may serve as a critical test of dynamics impacts that are missing in the 1D or 2D models. Continuous network measurements and long-term satellite measurements of $\mathrm{NO}_{2}$ are crucial for further improving our ability to understand the coupled effects of atmospheric dynamics and chemistry.

\section{Conclusions}

The response of $\mathrm{NO}_{2}$ to solar UV irradiance changes during the most recent two solar 11-year cycles was quantified using long-term observations from NDACC stations and compared with model simulations. 
We use EEMD approach to separate the $\mathrm{NO}_{2}$ solar-cycle signal from the variabilities of other time scales as well as the longer-term trend. A positive correlation between the extracted solarcycle mode of $\mathrm{NO}_{2}$ with solar Lyman- $\alpha$ is found for data over nine stations, while a negative correlation is reported for three stations. The stations with strong or moderate positive $\mathrm{NO}_{2}$ solarcycle responses are all located in the Northern Hemisphere, leaving the Southern Hemisphere stations with weak or negative $\mathrm{NO}_{2}$ responses. Further correlations with altitude show that the stations with the highest altitudes and the minimal interference of tropospheric variabilities have the strongest positive $\mathrm{NO}_{2}$ responses to solar cycles. At high latitudes where EPP could play a significant role in the stratospheric $\mathrm{NO}_{2}$ variabilities, the extracted solar cycle signals could include responses due to both solar UV and the EPP.

At low latitude where the EPP-induced $\mathrm{NO}_{2}$ signal is negligible, we use a 1-D photochemical model to study the direct UV-induced $\mathrm{NO}_{2}$ solar-cycle response definitively. The detailed analysis of the spectral responses of $\mathrm{NO}_{\mathrm{x}}$ and their precursor spices explains the spectral regions and the altitude ranges where $\mathrm{NO}_{\mathrm{x}}$ show positive or negative responses to the soalr UV changes. Our results suggest that the variability in $\mathrm{NO}_{2}$ and the corresponding $\mathrm{NO}_{\mathrm{x}}-\mathrm{O}_{3}$ chemistry plays an important role for $\mathrm{O}_{3}$ at the altitude range of about $20 \mathrm{~km}$ to near $60 \mathrm{~km}$, with $40 \mathrm{~km}$ being the center of the peak effect. Since $\mathrm{OH}$ variability and the $\mathrm{HO}_{\mathrm{x}}-\mathrm{O}_{3}$ chemistry is believed to control $\mathrm{O}_{3}$ variability at the upper middle atmosphere above $40 \mathrm{~km}$, our results suggests that, at the $40-$ $60 \mathrm{~km}$ region, the combined effects of $\mathrm{NO}_{x}$ and $\mathrm{HO}_{\mathrm{x}}$ likely determine the variability in the $\mathrm{O}_{3}$ catalytic loss. Above $60 \mathrm{~km}$, the chemical loss of $\mathrm{O}_{3}$ is likely dominated by $\mathrm{HO}_{\mathrm{x}}$ chemistry. Below $40 \mathrm{~km}, \mathrm{NO}_{\mathrm{x}}$ chemistry is more important. 
In contrast to the positive $\mathrm{NO}_{2}$ solar-cycle signal over most of the NDACC stations, the signal predicted by the $1 \mathrm{D}$ model is negative throughout the altitude region where $\mathrm{NO}_{\mathrm{x}}$ is important for $\mathrm{O}_{3}$, which agrees with the 2D modeling work by Gruzdev (2014), who showed that such a negative response holds almost globally except the deep polar regions. While the stations are located at remote areas or far from pollution sources, interferences from tropospheric $\mathrm{NO}_{2}$ cannot be completely ruled out. The fact that the NDACC stations reveal scattered $\mathrm{NO}_{2}$ responses at similar latitudes also suggests that dynamics may play an important role. Thus, we also investigate the $\mathrm{NO}_{2}$ solar-cycle signal simulated by WACCM-SD. We found hints of a complex seasonal difference in addition to the vertical and latitudinal patterns. The vertical profile of $\mathrm{NO}_{2}$ solar-cycle response is more complex than in the 1D model. In particular, the WACCM-SD results reveal a significant positive $\mathrm{NO}_{2}$ response at the bottom of the stratosphere at mid- and low-latitudes. This feature, together with the negative $\mathrm{UV}$-induced $\mathrm{NO}_{2}$ response (as shown by the $1 \mathrm{D}$ model results) and the EPP-induced response at high latitudes, creates a unique doublewell structure as a result of the coupled effects of atmospheric dynamics and chemistry. Continuous network measurements and long-term satellite measurements of $\mathrm{NO}_{2}$ are required to verify the simulated double-well structure.

This work provides new evidence of $\mathrm{NO}_{2}$ response to solar cycles to help resolve the longstanding puzzles in the field.

\section{Acknowledgments}

We acknowledge the support from the NASA Living with a Star (LWS) program ("Solar Forcing Impacts on Middle Atmospheric Ozone-controlling $\mathrm{HO}_{\mathrm{x}}$ and $\mathrm{NO}_{\mathrm{x}}$ Chemistry and Climate"). The 
$\mathrm{NO}_{2} \mathrm{VCD}$ data used in this publication were obtained from the Network for the Detection of Atmospheric Composition Change (NDACC) and are publicly available (www.ndaccdemo.org/). We thank Valery P. Sinyakov at the Kyrgyz National University, Kyrgyz Republic, for sharing data over Issyk-Kul, Michel Van Roozendael and François Hendrick at the Belgian Institute for Space Aeronomy (BIRA-IASB) for sharing data over the Jungfraujoch and Harestua, Udo Frieß at the Institute of Environmental Physics, University of Heidelberg, for sharing data over Neumayer (Frieß, et al., 2005), Geraint Vaughan at University of Manchester for sharing data over Aberystwyth, Paul V. Johnston (Emeritus) at the National Institute of Water \& Atmospheric Research Ltd (NIWA), New Zealand, for sharing data over Kiruna. The solar Lyman-alpha composite used in this work includes measurements from multiple instruments and models. It was provided by Martin Snow from the LASP Interactive Solar Irradiance Datacenter (lasp.colorado.edu/lisird/ ).

\section{Disclosure of Potential Conflicts of Interest}

The authors declare that they have no conflicts of interest.

\section{References}

Allen, M., Lunine, J.I., Yung, Y.L.: 1984, The vertical distribution of ozone in the mesosphere and lower thermosphere. J. Geophys. Res. 89, 4841, doi:10.1029/JD089iD03p04841.

Allen, M., Yung, Y.L., Waters, J.W.: 1981, Vertical transport and photochemistry in the terrestrial mesosphere and lower thermosphere (50-120km). J. Geophys. Res. 86, 3617, doi:10.1029/JA086iA05p03617. 
Ball, W.T., Mortlock, D.J., Egerton, J.S., Haigh, J.D.: 2014, Assessing the relationship between spectral solar irradiance and stratospheric ozone using Bayesian inference. J. Space Weather Space Clim. 4, A25, doi:10.1051/swsc/2014023.

Bauer, R., Rozanov, A., McLinden, C.A., Gordley, L.L., Lotz, W., Russell III, J.M., Walker, K.A., et al.: 2012, Validation of SCIAMACHY limb $\mathrm{NO}_{2}$ profiles using solar occulation measurements. Atmos. Meas. Tech., 5, 1059-1084, doi:10.5194/amt-5-1059-2012.

Beig, G., Fadnavis, S., Schmidt, H., Brasseur, G.P.: 2012, Inter-comparison of 11-year solar cycle response in mesospheric ozone and temperature obtained by HALOE satellite data and HAMMONIA model. J. Geophys. Sci. 117, D00P10, doi:10.1029/2011JD015697.

Boersma, K. F., Eskes, H. J., Dirksen, R. J., van der A, R. J., Veefkind, J. P., Stammes, P., Huijnen, V., et al.: 2011, An improved retrieval of tropospheric $\mathrm{NO}_{2}$ columns from the Ozone Monitoring Instrument. Atmos. Meas. Tech., 4, 1905-1928, doi:10.5194/amt-4-1905-2011.

Brasseur, G.P. and Solomon. S.: 2005, Aeronomy of the middle atmosphere: Chemistry and physics of the stratosphere and mesosphere. Third edition, Springer, Dordrecht, the Netherlands.

Dirksen, R.J., Boersma, K.F., Eskes, H.J., Ionov, D.V., Bucsela, E.J., Levelt, P.F., Kelder, H.M.: 2011, Evaluation of stratospheric $\mathrm{NO}_{2}$ retrieved from the Ozone Monitoring Instrument: Intercomparison, diurnal cycle, and trending. J. Geophys. Res., 116, D08305, doi:10.1029/2010JD014943.

Ermolli, I., Matthes, K., Dudok de Wit, T., Krivova, N.A., Tourpali, K., Weber, M., et al.: 2013, Recent variability of the solar spectral irradiance and its impact on climate modeling. Atmos. Chem. Phys. 13, 3945, doi:10.5194/acp-13-3945-2013. 
Frieß, U., Kreher, K., Johnston, P., Platt, U.: 2005, Ground-based DOAS measurements of stratospheric trace gases at two Antarctic stations during the 2002 ozone hole period, J. Atmos. Sci. 62,765 .

Garcia, R.R., López-Puertas, M., Funke, B., Marsh, D.R., Kinnison, D.E., Smith, A.K., and González-Galindo F.: 2014, On the distribution of $\mathrm{CO}_{2}$ and $\mathrm{CO}$ in the mesosphere and lower thermosphere, J. Geophys. Res. Atmos. 119, 5700-5718, doi:10.1002/2013JD021208.

Gruzdev, A.N.: 2008, Latitudinal dependence of variations in stratospheric $\mathrm{NO}_{2}$ content. Atmos. Ocean. Phys. 44, 319, doi:10.1134/S0001433808030079.

Gruzdev, A.N.: 2009, Latitudinal structure of variations and trends in stratospheric $\mathrm{NO}_{2}$. Int. J. Rem. Sens. 30, 4227, doi:10.1080/01431160902822815.

Gruzdev, A.N.: 2014, Estimate of the effects of Pinatubo eruption in stratospheric $\mathrm{O}_{3}$ and $\mathrm{NO} 2$ contents taking into account the variations in the solar activity. Atmos. Oceanic Opt. 27, 403, doi:10.1134/S102485601405008X.

Haigh, J.D., Winning, A.R., Toumi, R., Harder, J.W.: 2010, An influence of solar spectral variations on radiative forcing of climate. Nature 467, 696, doi:10.1038/nature09426.

Hendrick, F., Mahieu, E., Bodeker, G.E., Boersma, K.F., Chipperfield, M.P., De Maziere, M., et al.: 2012, Analysis of stratospheric $\mathrm{NO}_{2}$ trends2 trends above Jungfraujoch using groundbased UV-visible, FTIR, and satellite nadir observations. Atmos. Chem. Phys. 12, 8851-8864., doi:10.5194/acpd-12-8851-2012.

Hood, L.L., Soukharev, B.E.: 2006, Solar induced variations of odd nitrogen: Multiple regression analysis of UARS HALOE data. Geophys. Res. Lett. 33, L22805. doi:10.1029/2006GL028122. 
Huang, N.E., Shen, Z., Long, S.R., Wu, M.L.C., Shih, H.H., Zheng, Q.N., et al.: 1998, The empirical mode decomposition and the Hilbert spectrum for nonlinear and non-stationary time series analysis. Proc. R. Soc. Lond. A 454, 903, doi:10.1098/rspa.1998.0193.

Jacob, D. J.: 1999, Introduction to Atmospheric Chemistry,. Princeton University Press.

Johnston, P. V., McKenzie, R. L.: 1989, $\mathrm{NO}_{2}$ observations at $45^{\circ}$ S during the decreasing phase of solar cycle 21, from 1980 to 1987. J. Geophys. Res. 94, 3473, doi:10.1029/JD094iD03p03473.

Kobayashi-Kirschvink, K.J., Li, K. F., Shia, R.-L. Yung, Y.L.: 2012, Fundamental modes of atmospheric CFC-11 from empirical mode decomposition. Adv. Adaptive Data Anal. 4, 1250024, doi:10.1142/S1793536912500240.

Langematz, U., Grenfell, J.L., Matthes, K., Mieth, P., Kunze, M., Steil, B., and Bruhl, C.: 2005, Chemical effects in 11-year solar cycle simulations with the Freie Universität Berlin Climate Middle Atmosphere Model with online chemistry (FUB-CMAM-CHEM). Geophys. Res. Lett., 32, L13803, doi: 10.1029/2005GL022686.

Li, K.-F., Zhang, Q., Tung, K.-K., Yung, Y.L.: 2016, Resolving a long-standing modelobservation discrepancy on ozone solar cycle response. Earth and Space Sci. 431. doi:10.1002/2016EA000199.

Liley, J.B., Johnson, P.V., McKenzie, R.L., Thomas, A.J., Boyd, I.S.: 2000, Stratospheric $\mathrm{NO}_{2}$ variations from a long time series at Lauder, New Zealand. J. Geophys. Res. 105, 11633-11640, doi:10.1029/1999JD901157.

Machol, J., Snow, M., Woodraska, D., Woods, T., Viereck, R., Coddington, O.: 2019, An improved Lyman-Alpha composite. Earth Space Sci. 6, 2263. doi: 10.1029/2019EA000648. 
Maeda, S., Fuller-Rowell, T.J., and Evans, D.S.: 1989, Zonally averaged dynamical and compositional response of the thermosphere to auroral activity during September 18-24, 1984, J. Geophys. Res., 94(A12), 16869-16883, doi:10.1029/JA094iA12p16869.

Marsh, D., Mills, M.J., Kinnison, D.E., Garcia, R.R., Lamarque, J.-F., Calvo, N.: 2013, Climate change from 1850-2005 simulated in CESM1 (WACCM). J. Climate 26, 7372-7391, doi:10.1175/JCLI-DD-12-00558.1.

Merkel, A.W., Harder, J.W., Marsh, D.R., Smith, A.K., Fontenla, J.M., Woods, T.N.: 2011, The impact of solar spectral irradiance variability on middle atmospheric ozone. Geophys. Res. Lett. 38, L13802, doi:10.1029/2011GL047561.

Mills, F. P., Cageao, R.P., Sander, S.P., Allen, M., Yung, Y.L., Remsberg, E.E., et al.: 2003, OH Column Abundance Over Table Mountain Facility, California: Intra-annual Variations and Comparisons to Model Predictions for 1997-2001. J. Geophys. Res. Atmos, 108, 4785, doi:10.1029/2003JD003481.

Morgenstern, O., Hegglin, M.I., Rozanov, E., O'Connor, F.M., Abraham, N.L., Akiyoshi, H., et al.: 2017, Review of the global models used within phase 1 of the Chemistry-Climate Model Initiative (CCMI), Geosci. Model Dev. 10, 639, doi:10.5194/gmd-10-639-2017.

Newman, S., Xu, X., Gurney, K.R., Hsu, Y.K., Li, K.L., Jiang, X., et. al.: 2016, Toward consistency between trends in bottom-up $\mathrm{CO}_{2}$ emissions and top-down atmospheric measurements in the Los Angeles megacity. Atmos. Chem. Phys. 16, 3843, doi: 10.5194/acp-163843-2016.

Peck, E.D., Randall, C.E., Harvey, V.L. and Marsh, D.R.: 2015, Simulated solar cycle effects on the middle atmosphere: WACCM3 Versus WACCM4, J. Adv. Model. Earth Syst., 7, 806-822, 
doi:10.1002/2014MS000387.

Remsberg, E.E.: 2008, On the response of Halogen Occultation Experiment (HALOE) stratospheric ozone and temperature to the 11-year solar cycle forcing. J. Geophys. Res. 113, D22304., doi:10.1029/2008JD010189.

Remsberg, E.E.: 2008, On the response of Halogen Occultation Experiment (HALOE) stratospheric ozone and temperature to the 11-year solar cycle forcing. J. Geophys. Res. 113, D22304., doi:10.1029/2008JD010189.

Remsberg, E.E.: 2013, Decadal-scale responses in middle and upper stratospheric ozone from SAGE II version 7 data. Atmos. Chem. Phys. Discuss. 13, 20239, doi:10.5194/acpd-13-202392013.

Rusch, D.W., Gerard, J.-C., Solomon, S., Crutzen, P.J., and Reid, G.C.: 1981, The effect of particle precipitation events on the neutral and ion chemistry of the middle atmosphere - I. odd nitrogen. Planet Space Sci. 29(7), 767 - 774.

Semeniuk, K., Fomichev, V.I., McConnell, J.C., Fu, C., Melo, S.M.L, and Usoskin, I.G.: 2011, Middle atmosphere response to the solar cycle in irradiance and ionizing particle precipitation. Atmos. Chem. Phys., 11, 5045-5077, doi:10.5194/acp-11-5045-2011.

Shi, Y., Li, K.-F., Yung, Y.L., Aumann, H.H., Shi, Z., Hou, T.Y.: 2013, Principal modes of variability in the tropics from 9-Year AMSU data. Climate Dyn. 41, 1385, doi:10.1007/s00382013-1696-x.

Solanki, S.K., Krivova, N.A., Haigh, J.D.: 2013, Solar irradiance variability and climate. Annual Ann. Rev. of Astron. Astrophys. 51, 311. doi:10.1146/annurev-astro-082812-141007.

Solomon, S.: 1999, Stratospheric ozone depletion: A review of concepts and history. Rev. 
Geophys. 37, 275. doi:10.1029/1999RG900008.

Swartz, W.H., Stolarski, R.S., Oman, L.D., Fleming, E.L., Jackman, C.H.: 2012, Middle atmosphere response to different descriptions of the 11-yr solar cycle in spectral irradiance in a chemistry-climate model. Atmos. Chem. Phys., 12, 5937, doi:10.5194/acp-12-5937-2012.

Tapping, K.F.: 2013, The $10.7 \mathrm{~cm}$ solar radio flux (F10.7), Space Weather 11, 394, doi:10.1002/swe.20064.

Wang, S., Li, K-F., Pongetti, T.J., Sander, S.P., Yung, Y.L., Liang, M.-C., et al.: 2013, Atmospheric OH response to the most recent 11-year solar cycle. Proc. Natl. Acad. Sci. 110, 2023-2028, doi: 10.1073/pnas.1117790110

Wang, S., Zhang, Q., Millan, L., Li, K.-F., Yung, Y.L., Sander, S.P., et al.: 2015, First evidence of middle atmospheric $\mathrm{HO}_{2}$ response to 27-day solar cycles from satellite observations. Geophys. Res. Lett. 42, 10004, doi:10.1002/2015GL065237.

Woods, T.N., Tobiska, W.K., Rottman, G.J., Worden, J.R.: 2000, Improved solar Lyman $\alpha$ irradiance modeling from 1947 through 1999 based on UARS observations. J. Geophys. Res. Space Phys. 105, A12, 27195. doi: 10.1029/2000JA000051.

Wu, Z., Huang, N.E.: 2009, Ensemble empirical mode decomposition: A noise-assisted data analysis method. Adv. Adaptative Data Analysis 1, 1, doi:10.1142/S1793536909000047.

Yung, Y.L., DeMore, W.D.: 1999, Photochemistry of Planetary Atmospheres, Oxford University Press, Oxford.

\section{Figure Captions}


(a) Time Series

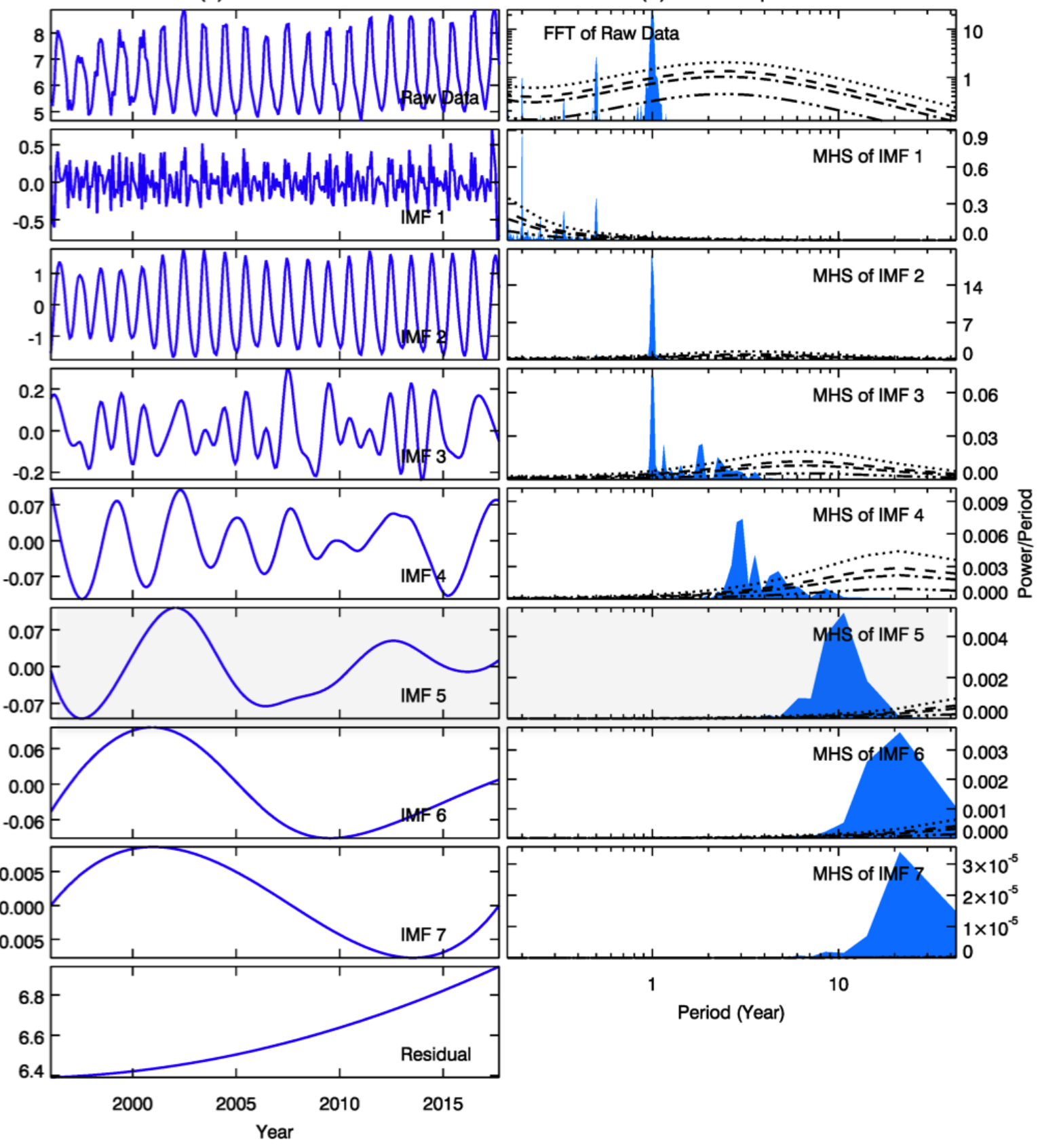

Figure 1. EEMD decomposition results for station Issyk-Kul. Left panels are timeseries of $\mathrm{NO}_{2}$ signals $\left[10^{15} \mathrm{~cm}^{-2}\right]$, with the raw data on the top and decomposed signals below. Right columns show the corresponding power spectra. For the raw data, the power spectrum is obtained using the fast Fourier transform (FFT). For the IMFs, the power spectrum is obtained using the 
marginal Hilbert spectrum (MHS). The residual is the longer-term trend on top of the baseline value. In this case, IMF 5 represents the solar 11-year cycle signal of $\mathrm{NO}_{2}$. 
(a) Time Series

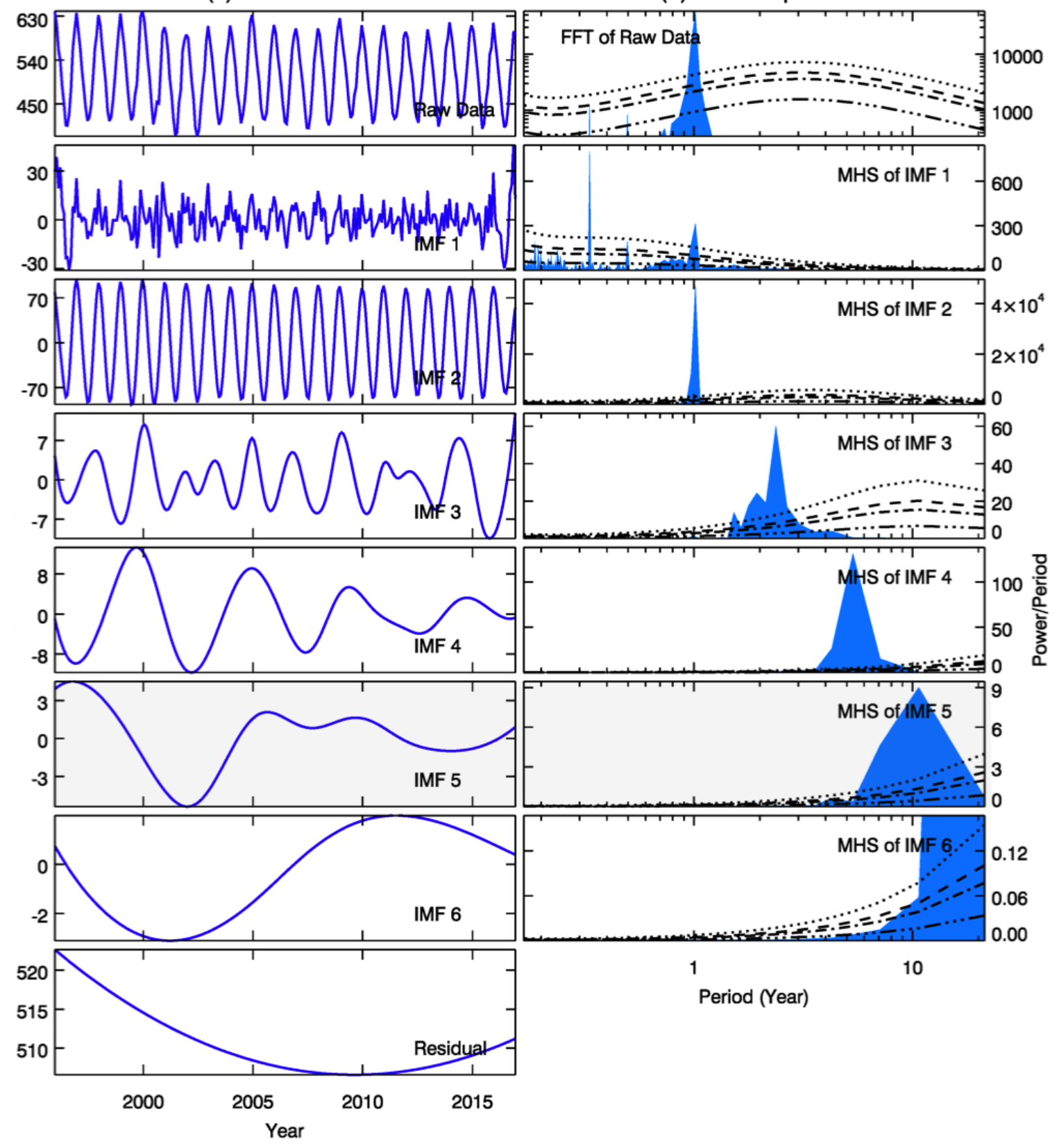

Figure 2. EEMD decomposition results for station Kerguelen. Left panels are signals, with the raw data $\left[10^{13} \mathrm{~cm}^{-2}\right]$ on the top and decomposed signals below. Right columns show the corresponding power spectra. The residual is the longer-term trend on top of the baseline value. In this case, IMF 5 represents the solar 11-year cycle signal of $\mathrm{NO}_{2}$. 
For $100 \%$ increase of Solar Lyman- $\alpha$, NO2 VCD increases by $(9.3+/-0.4) \%$

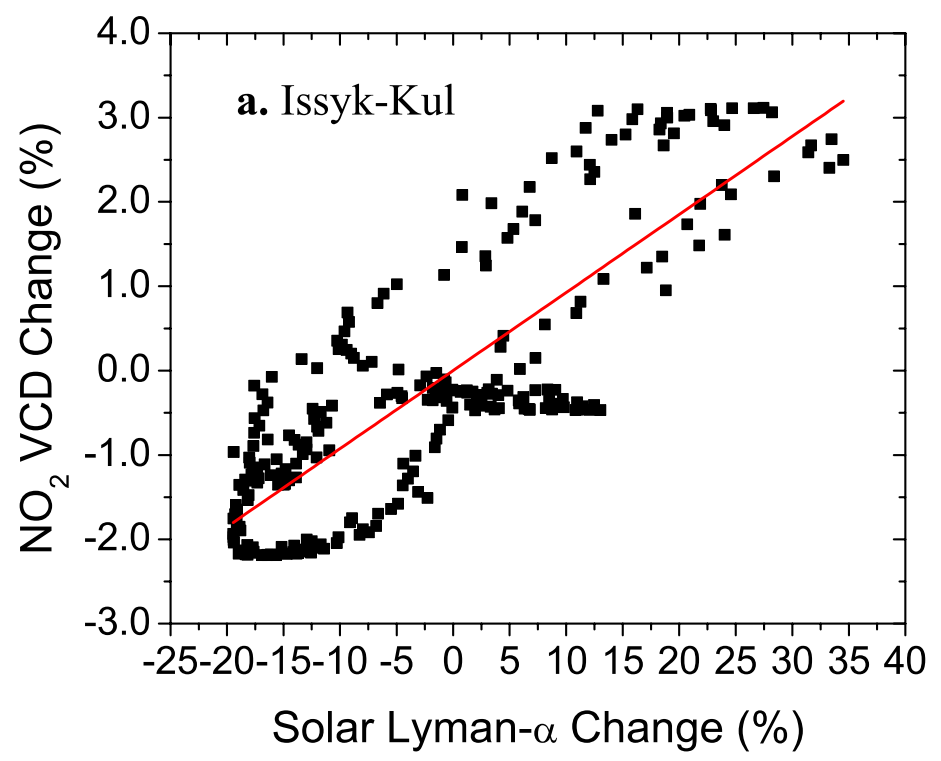

For $100 \%$ increase of Solar Lyman- $\alpha$, NO2 VCD increases by $-(2.7+/-0.1) \%$

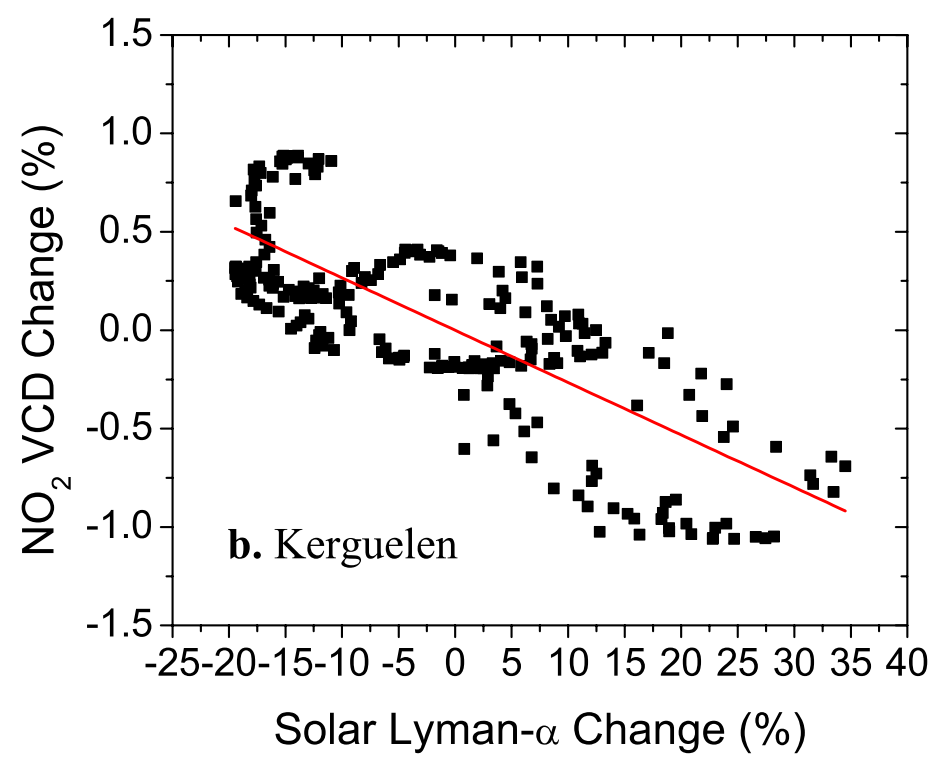

Figure 3. Linear correlation of the extracted $\mathrm{NO}_{2}$ solar-cycle signal (from Figs. 1 and 2) and Solar Lyman- $\alpha$ changes at station Issyk-Kul (top) and Kerguelen (bottom). 


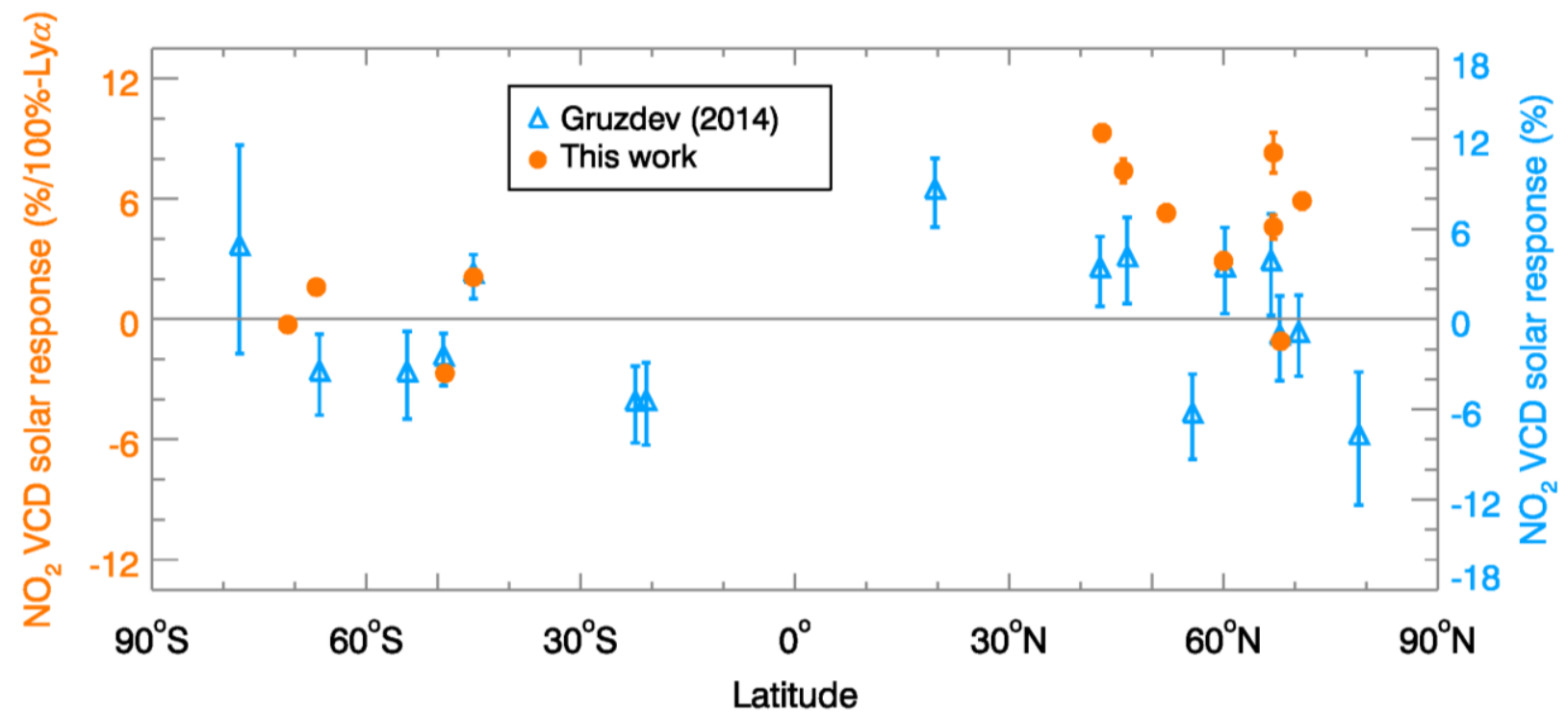

Figure 4. Latitudinal pattern of the $\mathrm{NO}_{2}$ sensitivity to solar Lyman- $\alpha$ change. The analysis results from this study are shown in orange. The numbers stand for percentage change in $\mathrm{NO}_{2} \mathrm{VCD}$ with $100 \%$ change in solar Lyman- $\alpha$. The $\mathrm{NO}_{2} \mathrm{VCD}$ solar-cycle variability [\%] from Gruzdev (2014) is shown in blue. 


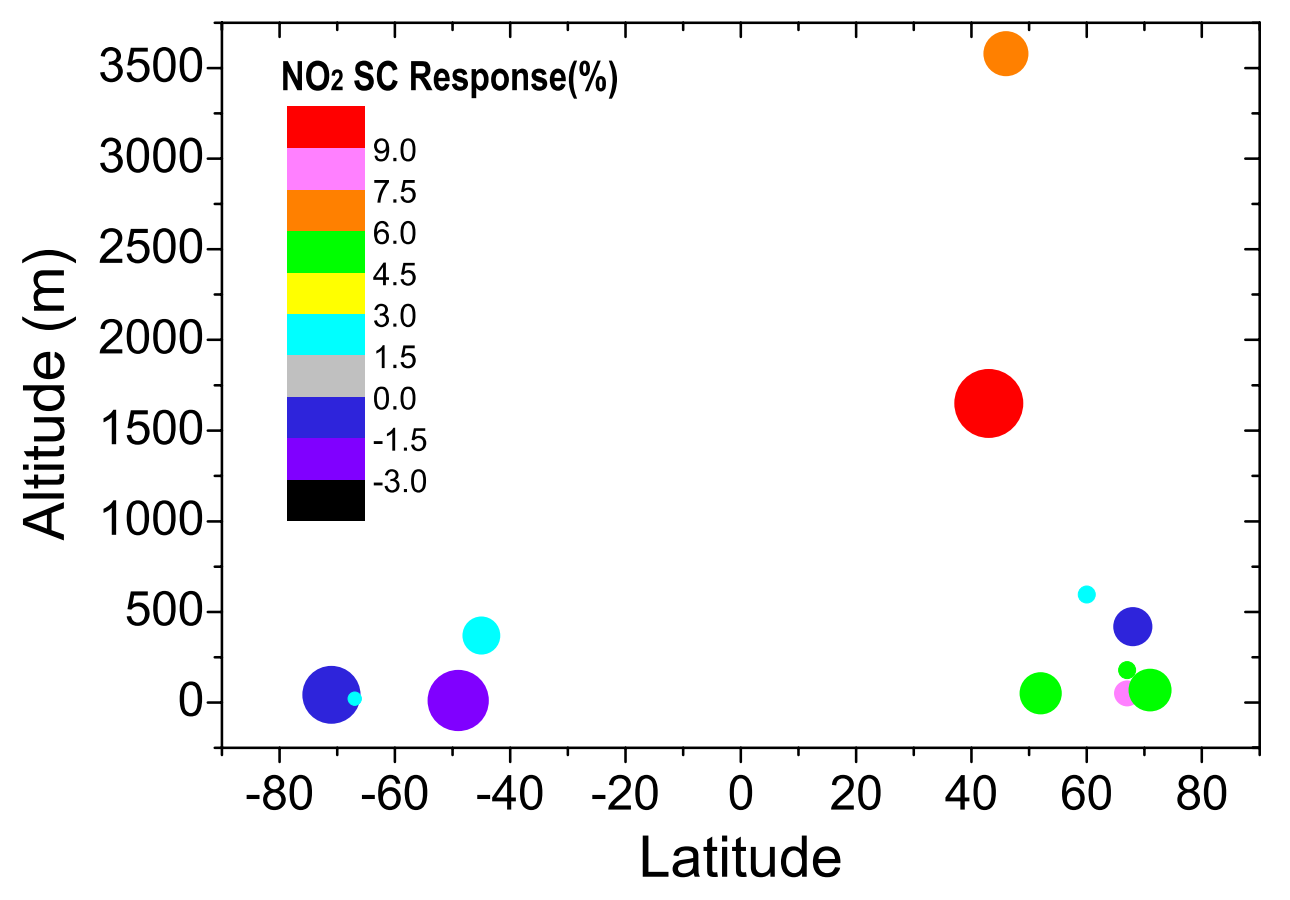

Figure 5. The altitude and latitude dependence of the $\mathrm{NO}_{2}$ sensitivity to solar Lyman- $\alpha$ change. The scatters are color-coded according to the percentage change in $\mathrm{NO}_{2} \mathrm{VCD}$ with $100 \%$ change in solar Lyman- $\alpha$. The sizes of the scatters are proportional to the correlation coefficient $\left[R^{2}\right]$ from Table 1. 

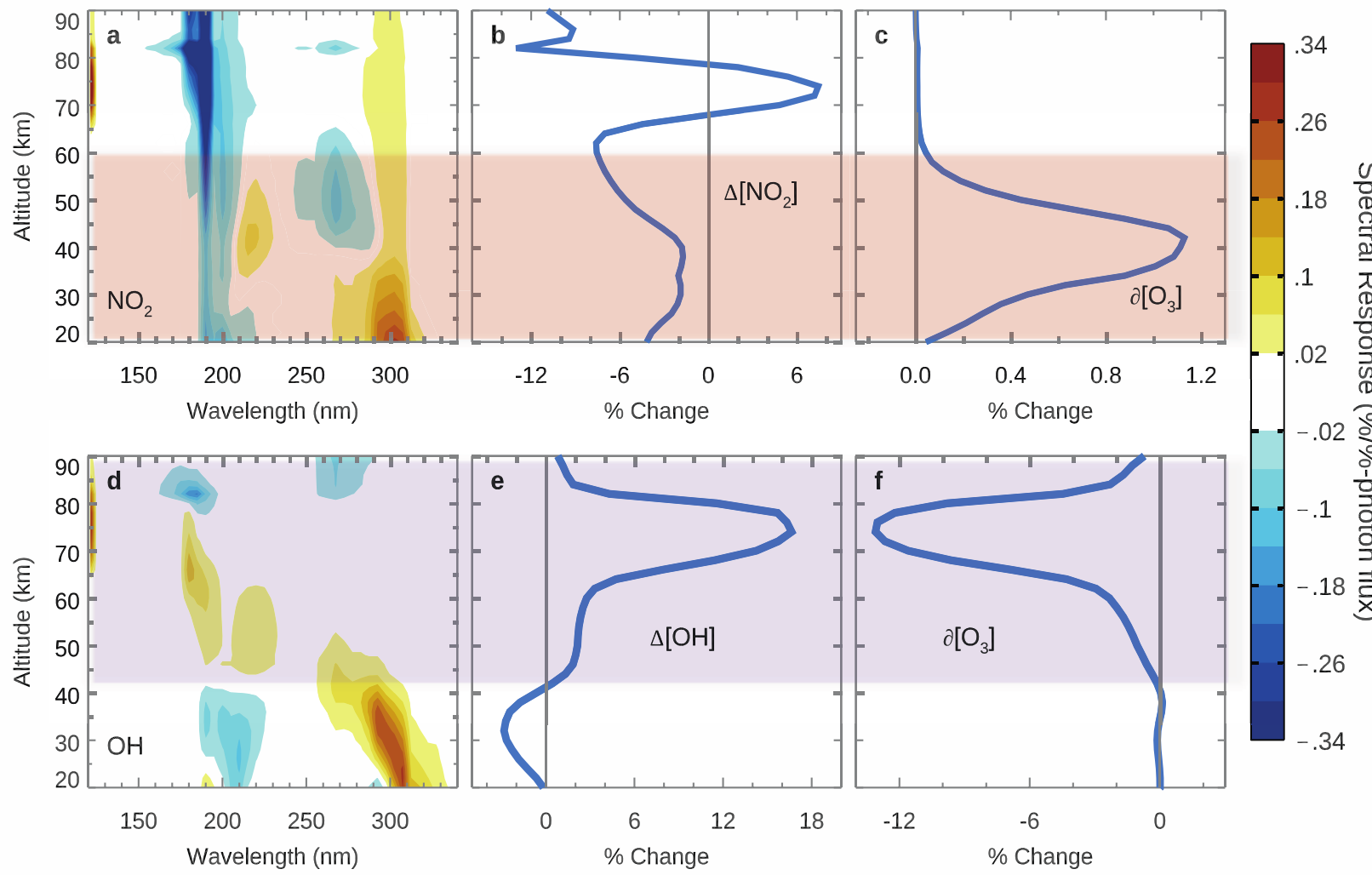

Figure 6. Vertical profile of $\mathrm{NO}_{2}$ solar-cycle signal in comparison with $\mathrm{OH}$ solar-cycle signal and their implications for $\mathrm{O}_{3}$ from the $1 \mathrm{D}$ model. (a) The vertically and spectrally resolved $\mathrm{NO}_{2}$ response (\% change in $\mathrm{NO}_{2}$ ) to changes in solar UV irradiance (\% change in the photon flux). (b) Vertical profiles of $\mathrm{NO}_{2}$ solar-cycle signal from the model. (c) The corresponding $\mathrm{O}_{3}$ variability solely due to the changes in $\mathrm{NO}_{2}$ in Panel $\mathrm{b}$. The highlighted altitude region $(\approx 20-60 \mathrm{~km})$ shows where $\mathrm{NO}_{2}$ solar-cycle changes have significant impacts on $\mathrm{O}_{3}$. Panels $\mathrm{d}$, e, and $\mathrm{f}$ are the same as Panels a, b, and c except that they are for $\mathrm{OH}$ instead of $\mathrm{NO}_{2}$. The highlighted altitude region $(\approx 40-90 \mathrm{~km})$ shows where $\mathrm{OH}$ solar-cycle changes have significant impacts on $\mathrm{O}_{3}$. See more details in Wang et al. (2013). 

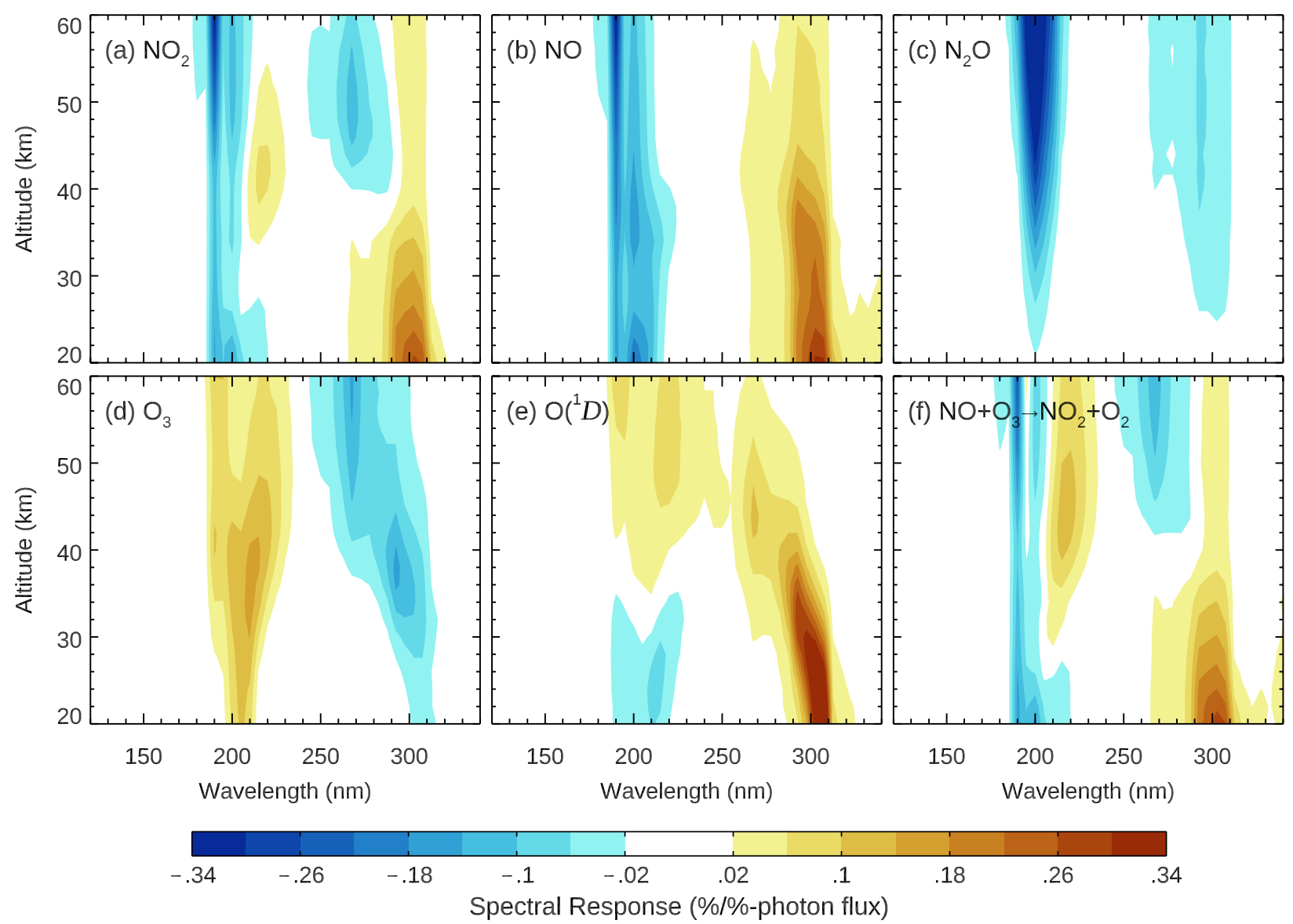

Figure 7. The vertically and spectrally resolved response of chemical species and key chemical reaction rate [\% change] to the changes in solar UV irradiance [\% change in the photon flux]. 


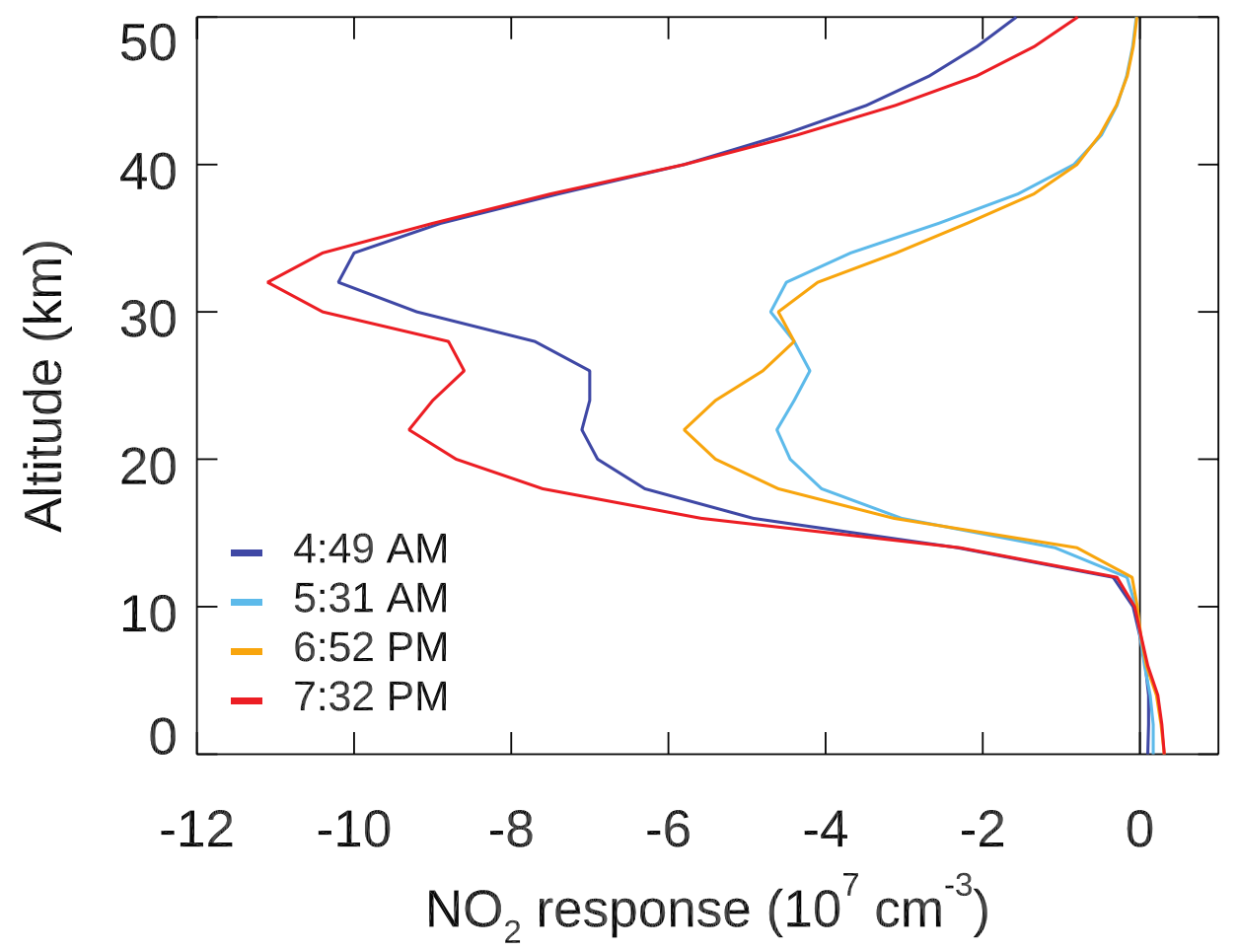

Figure 8 . Changes in $\mathrm{NO}_{2}$ number density $\left[10^{7}\right.$ molecules $\left.\mathrm{cm}^{-3}\right]$ between solar maximum and solar minimum (January 2002 and November 2007) at different times around sunrise and sunset. 

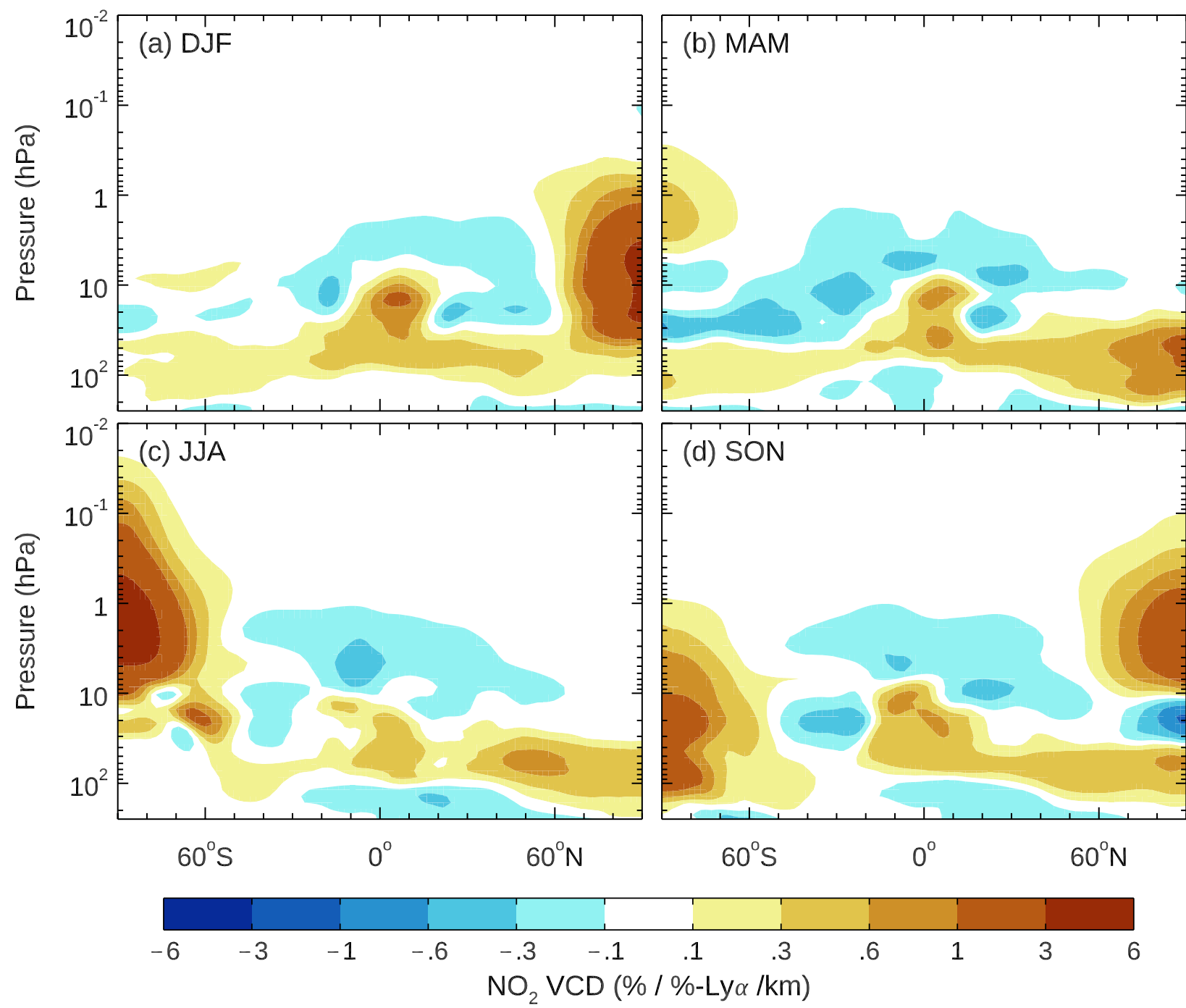

Figure 9. CCMI WACCM SD model run from 1979 to 2014. The $\mathrm{NO}_{2}$ solar-cycle response in each of the four seasons is shown as the corresponding changes in $\mathrm{NO}_{2} \mathrm{VCD}(\%)$ per $100 \%$ change in solar Lyman- $\alpha$ changes at each vertical interval of $1 \mathrm{~km}$. (a) December - February, (b) March - May, (c) June - August, (d) September - November. 


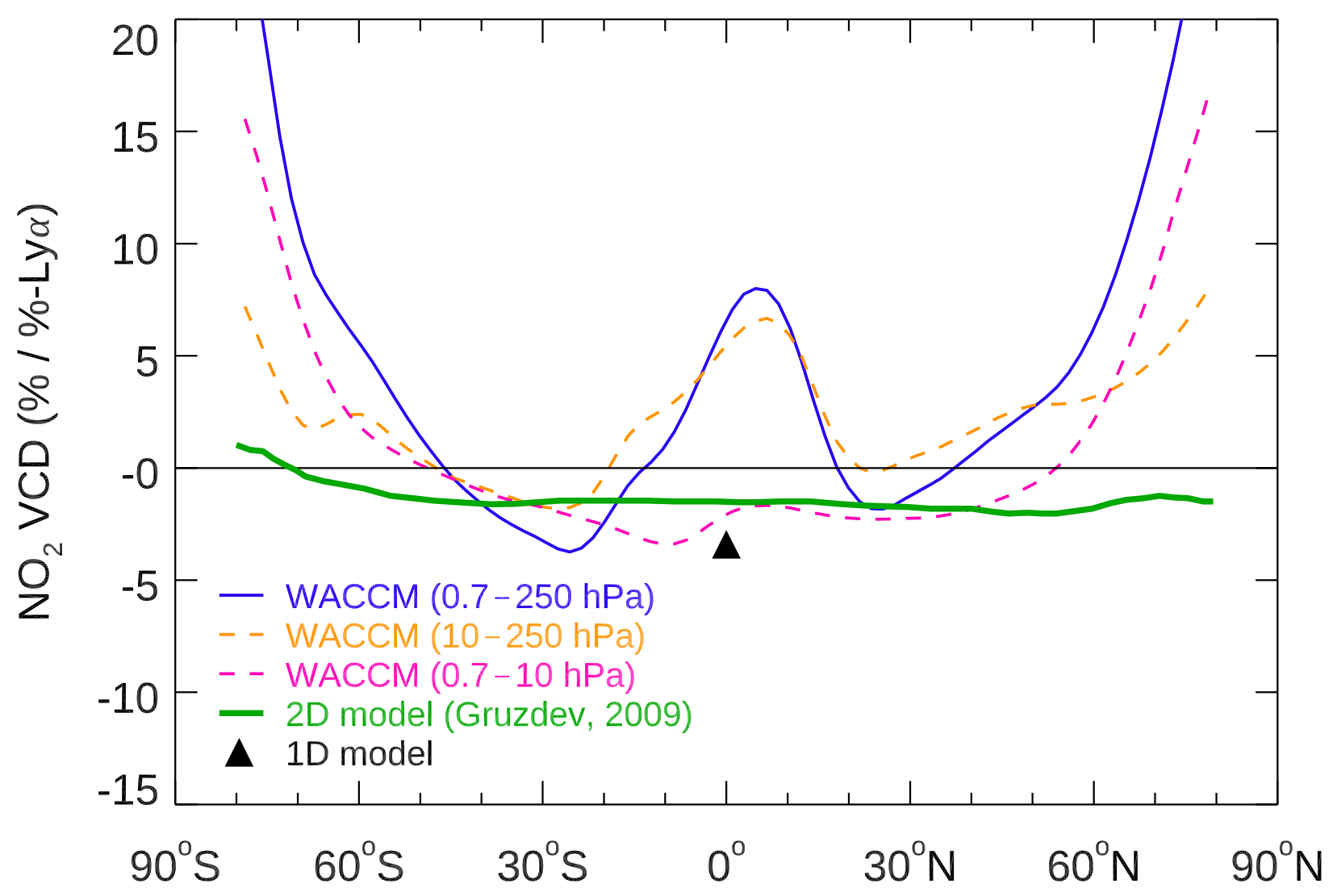

Figure 10. The 11-year solar-cycle response of vertically integrated $\mathrm{NO}_{2}$ from the WACCM Specified Dynamics (WACCM-SD) model run. The blue, orange, and pink lines represent results from different vertical ranges of the $\mathrm{NO}_{2}$ column integration. The results of the $2 \mathrm{D}$ model used by Gruzdev (2009) are shown by the green-thick line. The corresponding result of the 1D model in this work (24-hour diurnal average) is marked by the black triangle. The unit is $\%-\mathrm{NO}_{2} \mathrm{VCD}$ change/100\%-Lyman- $\alpha$ change (refer to the $y$-axis on the left). 
Station Latitude Longitude Altitude $\mathrm{NO}_{2}$ solar-cycle signal Error $R^{2}$

$\left[{ }^{\circ}\right] \quad\left[{ }^{\circ}\right] \quad[\mathrm{m} \mathrm{ASL}] \quad[\%$ change $/ 100 \%$ change in

Lyman- $\alpha]$

$\begin{array}{lrrrrll}\text { Neumayer } & -70.62 & 8.37 \mathrm{E} & 42 & -0.27 & 0.02 & 0.58 \\ \text { Dumont } & -66.67 & 140.0 \mathrm{E} & 20 & 1.6 & 0.2 & 0.14 \\ \text { Kerguelen } & -49.3 & 70.3 \mathrm{E} & 10 & -2.7 & 0.1 & 0.61 \\ \text { Lauder } & -45.04 & 169.68 \mathrm{~W} & 370 & 2.1 & 0.2 & 0.38 \\ \text { Issk-Kul } & 42.6 & 77.0 \mathrm{E} & 1650 & 9.3 & 0.4 & 0.69 \\ \text { Jungfraujoch } & 46.55 & 7.98 \mathrm{E} & 3580 & 7.4 & 0.6 & 0.45 \\ \text { Aberystwyth } & 52.4 & 4.1 \mathrm{~W} & 50 & 5.3 & 0.4 & 0.42 \\ \text { Harestua } & 60.2 & 10.8 \mathrm{E} & 596 & 2.9 & 0.4 & 0.18 \\ \text { Zhigansk } & 66.8 & 123.4 \mathrm{E} & 50 & 8.3 & 1 & 0.26 \\ \text { Sodankyla } & 67.37 & 26.65 \mathrm{E} & 179 & 4.6 & 0.6 & 0.18 \\ \text { Kiruna } & 67.84 & 20.41 \mathrm{E} & 419 & -1.1 & 0.1 & 0.39 \\ \text { Scorebysund } & 70.48 & 21.97 \mathrm{~W} & 68 & 5.9 & 0.4 & 0.43\end{array}$

Table 1 . Summary of the 12 stations with significant $\mathrm{NO}_{2}$ solar-cycle signal.

The $\%$ response in $\mathrm{NO}_{2} \mathrm{VCD}$ is determined by the slope in the linear correlation between $\mathrm{NO}_{2}$ changes and Lyman- $\alpha$ changes (as shown in Fig. 3). The error bar is determined by the uncertainty of the linear regression. The correlation coefficient $\left[R^{2}\right]$ represents the goodness of the linear fit. 